\title{
Alimentation animale et valeur nutritionnelle induite sur les produits dérivés consommés par I’homme : Les lipides sont-ils principalement concernés ?
}

Oléagineux, Corps Gras, Lipides. Volume 10, Numéro 5-6, 405-24, Double 5-6, SEPTEMBRE-OCTOBRENOVEMBRE-DÉCEMBRE 2003, FONDAMENTAL

Auteur(s) : Jean-Marie BOURRE, .

Author(s) : Jean-Marie BOURRE

Résumé : Dans quelle mesure la nourriture reçue par les animaux induit-elle une modification (amélioration ou au contraire dégradation) de la valeur nutritionnelle des aliments qui en sont issus pour la nourriture de l'homme ? La réponse à cette question varie selon la nature des nutriments (vitamines, minéraux, acides gras poly-insaturés indispensables des graisses, acides aminés indispensables des protéines), et aussi de l'espèce considérée. Le problème est de rechercher l'impact réel des formulations des rations utilisées dans les élevages sur la valeur nutritionnelle des produits (viandes, lait et laitages, fromages et œufs, etc.), et donc leur influence sur la santé du consommateur, évidemment dans un sens favorable. Les acides gras poly-insaturés oméga-3 ( $\omega 3$ ) bénéficient de deux grands axes de valorisation. Le premier réside dans leur importance quantitative et leurs rôles dans le cadre de la mise en place et du maintien de divers organes, le cerveau au premier chef. Le second se trouve dans la prévention de diverses pathologies, les maladies cardiovasculaires occupant une place prépondérante $\backslash$; avec, depuis peu, les maladies neuropsychiatriques, stress, dépression et démence. Compte tenu des implications en termes de maladies, cardio-cérébro-vasculaires entre autres, le contrôle de la nature des acides gras constitutifs des graisses représente donc un enjeu considérable en ce qui concerne les viandes issues d'animaux terrestres, maritimes et aériens, du lait, des laitages, fromages et des œufs. Car la qualité des graisses données en nourriture animale détermine fondamentalement la valeur nutritionnelle des aliments qui en sont dérivés, pour la consommation humaine. Bien évidemment, il est relativement difficile de modifier la composition en acides gras des phospholipides constitutifs des membranes biologiques intégrées dans la multitude de types cellulaires, dont la spécificité est largement sous contrôle génétique. En revanche, la nature des acides gras des triglycérides de réserve (trouvés en quantité plus ou moins importante selon les localisations anatomiques c'est-à-dire les morceaux de boucherie) peut varier notablement en fonction de la nourriture reçue par les animaux. En les contrôlant, il est possible de contribuer à un meilleur état sanitaire des consommateurs. Les conséquences (qualitatives et quantitatives) des modifications de la composition de l'alimentation animale sur la valeur des produits dérivés consommés par l'homme sont plus amples chez les monogastriques que chez les poly-gastriques. Car, par exemple, les bactéries intestinales hydrogénantes de ces derniers transforment en acides gras saturés une fraction notable des acides gras poly-insaturés présents dans leur alimentation, leur faisant par conséquent perdre leur intérêt biologique. Ainsi, dans les meilleures conditions, en nourrissant par exemple les animaux avec des graines de lin ou de colza, la teneur en acide alpha-linolénique est multipliée par environ 2 dans la viande de bœuf, par 6 dans celle de porc, par 10 dans le poulet, par 40 dans les œufs. En nourrissant les animaux avec des extraits de poissons ou d'algues (huiles), la quantité de DHA (acide cervonique, 22:6w3) est 
multipliée par 2 dans la viande de bœuf, par 7 dans le poulet, par 6 dans les œufs, par 20 dans le poisson (saumon). Pour obtenir de tels résultats, il ne s'agit que de respecter la physiologie des animaux, ce qui était fréquemment le cas avec les méthodes traditionnelles. Il convient de mettre l'accent sur les poissons, dont la valeur nutritionnelle pour l'homme en termes de lipides (déterminée par la quantité d'acides gras oméga-3) peut varier considérablement selon la nature des graisses avec lesquelles les animaux sont alimentés. L'objectif de prévention de certains aspects des maladies cardio-vasculaires (et d'autres pathologies) peut être atteint ou au contraire contrarié selon la nature des acides gras présents dans la chair de poisson, conséquence directe de la nature des graisses avec lesquelles ils ont été nourris. II en est de même pour les œufs, les œufs " oméga-3 " étant en fait voisins des œufs naturels $\backslash$; point de valorisation considérable montrant leur intérêt : ils participent à la formulation de certains laits adaptés pour nourrissons, dont la composition est la plus proche de celle du lait de femme. Les glucides sont présents en quantités relativement faibles chez les animaux, sauf dans certains tissus, dans lesquels la teneur de glycogène n'est pas négligeable. De plus, les concentrations en glucides se modifient selon la qualité et la durée de la maturation après l'abattage, processus indispensable pour permettre de rendre la viande comestible. En tout état de cause, leur présence n'influe que sur les qualités organoleptiques, mais pas sur la valeur nutritionnelle glucidique. Bien que le muscle contienne des quantités importantes de protéines, leurs compositions, c'est-à-dire leurs profils en acides aminés, sont sous contrôle génétique. Pour une espèce donnée (et même une race), les modifications de l'alimentation des animaux peuvent induire des évolutions quantitatives au niveau des protéines, mais peu d'améliorations qualitatives. Une manipulation génétique susceptible d'enrichir en tel ou tel acide aminé indispensable est probablement illusoire, sauf pour le lait. Globalement, en ce qui concerne les mammifères, les oiseaux et les poissons, toutes inflexions importantes des minéraux et des vitamines dans la ration des animaux (par défaut ou par excès) peuvent perturber la physiologie des organes, et par conséquent les performances zootechniques, ce qui relève de l'examen vétérinaire \; exception faite de certaines vitamines lipo-solubles, en particulier de la vitamine $\mathrm{E}$, et, dans une moindre mesure de la vitamine D. Les faibles variations susceptibles d'être éventuellement obtenues ne permettraient toutefois pas de participer significativement à l'amélioration de la couverture de besoins nutritionnels de l'homme. Les produits tripiers font exception, mais ils ne sont plus consommés que marginalement et ne peuvent concourir significativement à la couverture moyenne des besoins en nutriments de l'homme. Toutefois, concernant les poissons, de notables différences peuvent être observées selon les lieux de pêche et les saisons (entre autres), et, par voie de conséquence très probable, selon les élevages (pour les vitamines $D$ et $E$, l'iode le fer et le sélénium). Pour les œufs, la composition varie beaucoup selon les formulations des aliments donnés aux poules pondeuses (principalement pour les vitamines $A, D$ et $E$ et plusieurs éléments, dont l'iode). Une nouvelle approche se dessine avec les micro-nutriments non indispensables pour l'homme trouvés dans les produits animaux destinés à la consommation humaine. Il s'agit, par exemple, des caroténoïdes liposolubles. Parmi ceux-ci, la lutéine et la zéaxanthine sont présentes dans le jaune de l'œuf, contribuant à sa coloration. Or, des travaux très récents montrent que ces molécules peuvent être quantitativement augmentées dans l'œuf par une alimentation appropriée des poules pondeuses. Point nouveau, la consommation d'œufs ainsi enrichis a permis d'accroître les concentrations des deux caroténoïdes dans le sang de volontaires humains, et par conséquent dans leur rétine. Par ailleurs, on sait que ces substances sont présentes dans l'œil, en particulier dans la rétine. Or, une augmentation de la prise alimentaire de lutéine et de zéaxanthine induit leur accroissement dans la rétine. D’autre part, il est bien connu que la cataracte comme la dégénérescence maculaire liée à 
l'âge sont presque 2 fois moins fréquentes chez les sujets dont la teneur de ces substances est grande dans le sang, par rapport à ceux dont la teneur est basse. D'autres molécules peuvent être impliquées : les CLA, dont les intérêts sont multiples, en particulier avec leur effet d'augmentation de la masse maigre et de diminution de la masse grasse \; et même peut-être une nouvelle "vitamine " décrite récemment comme telle, la vitamine PQQ (pirroloquinoline quinone), qui relèverait du groupe des vitamines B. Quelle est l'incidence sur les prix payés par les consommateurs ? En fait, pour les acides gras oméga-3, le surcoût reste modeste par rapport au gain considérable de valeur nutritionnelle : ainsi, l'augmentation de $5 \%$ du prix de l'œuf se traduit par une multiplication par 10 de son contenu en acides gras oméga-3, et par conséquent divise par presque autant le prix du gramme d'acide gras oméga-3. Pour le poisson il devrait en être de même [2]. L'acide alphalinolénique est trouvé de manière très privilégiée dans l'huile de colza, où il est le moins onéreux. Etant donné le déficit considérable des acides oméga-3 dans l'alimentation des Français (moins de $50 \%$ de apports recommandés pour l'acide alpha-linolénique), il convient de promouvoir les aliments qui apportent, quotidiennement dans une ration alimentaire usuelle, plusieurs décigrammes d'acide alpha-linolénique et\lou quelques centaines de milligrammes d'EPA + DHA, tout en respectant un rapport oméga-6/loméga-3 proche de 5 et en minimisant les quantités d'acides gras saturés. En alimentation usuelles il s'agit des huiles de colza et de noix (et, dans une moindre mesure, d'huile de soja), des poisson gras $\backslash$; et, à condition que la nourriture animale ait été correcte, des œufs et des poissons d'élevage.

Summary : Effect of animal feeding and nutritional value on derived products consumed by humans. Are lipids concerned nearly exclusively ? To what extent does the food given to animals lead to a modification (beneficial or otherwise) of the nutritional value of the food that humans eat ? The answer to this question varies according to the nature of the nutriment: vitamins, minerals, polyunsaturated fatty acids (an indispensable fat), amino acids (protein components, some being indispensable), and also the species. The problem is to determine the true impact of the formulations in chows used on farms and breeding centres on the nutritional value of the products (meat, milk and dairy products, cheese, and eggs, etc), and thus their effect on the health of consumers. Omega3 polyunsaturated fatty acids have two major virtues. The first lies in their quantitative abundance and their role in the development and maintenance of different organs, primarily the brain. The second is their role in the prevention of different pathologies, mainly the cardiovascular diseases, and more lately the neuropsychiatric disorders, from stress to depression and dementia. Bearing in mind the implications in terms of diseases, cardio-cerebro-vascular among others, control of the nature of fatty acids present in fats thus represents a considerable challenge in the case of meat derived from terrestrial or maritime animals and birds, or indeed of milk, dairy products, cheese, and eggs. Indeed, the quality of fats present in foodstuffs given to animals determines fundamentally the dietary value of the resulting foods intended for human consumption. Of course, it is relatively difficult to modify the fatty acid composition of phospholipids that are components of biological membranes integrated in a multitude of different cell types, whose specificity is largely under genetic control. On the other hand, the nature of fatty acids of reserve triglycerides (found in more or less large amounts depending on the anatomical localisation, that is to say the butcher's cuts) can vary mainly as a function of the food received by the animal. By controlling this, it is possible to improve the health of consumers. The consequences (qualitative and quantitative) of modifications in the composition of animal foods on the value of derived products consumed by humans are more marked when single-stomach animals are concerned than multi-stomach animals. Because, for 
example, hydrogenating intestinal bacteria of the latter group transform a large proportion of polyunsaturated fatty acids in their food into saturated fatty acids, thus depriving them of any biological interest. Under the best conditions, and feeding animals with extracts of linseed and rapeseed grains for example, the level of alpha-linolenic acid is increased approximatly two-fold in beef and six-fold in pork, ten-fold in chicken, and forty-fold in eggs. By feeding animals with fish extracts or algae (oils) the level of DHA (cervonic acid, 22:6, n-3) is increased approximately 2-fold in beef, 7-fold in chicken, 6-fold in eggs, and 20-fold in fish (salmon). To obtain such results, it is not sufficient to respect only the physiological needs of the animal, which was generally the case with traditional methods. It is important to stress the role of fish, whose nutritional value for humans in terms of lipids (determined by omega-3 fatty acid levels) can vary considerably according to the type of fats the animals have been fed. The aim of preventing some aspects of cardiovascular disease (and other pathologies) can be achieved, or on the contrary frustrated, depending on the nature of fatty acids present in fish flesh, the direct consequence of the nature of fats with which they have been fed. It is the same for eggs, "omega-3 eggs" being in fact more or less similar to natural eggs $\backslash$; which is a big point in their favour $\backslash$; they are used in the formulation of certain formula milks for infants, whose composition is closest to that of breast milk. Carbohydrates are present in relatively low amounts in animals, except in certain tissues in which the level of glycogen is moderate. Moreover, the concentration of carbohydrates changes depending on the quality and duration of the maturing process after slaughtering, an indispensable step for making meat comestible. In any case, the presence of carbohydrates affects only the organoleptic properties, but not nutritional values. Though muscles contain large amounts of protein, their compositions, that is to say their amino acid profiles, are under genetic control. For a given species (and even race), modification of animal feeding can induce quantitative changes at the protein level but little qualitative improvement. Genetic manipulation able to increase one or another indispensable amino acid is probably illusory, except for milk. In general, as far as mammals, birds, and fish are concerned, any major alterations in minerals and vitamins can perturb the physiology of organs, and consequently the results of breeding. Exceptions are some fat-soluble vitamins, in particular vitamin $E$, and to a lesser extent vitamin D. However, the small variations that might perhaps be obtained would not permit any significant improvement in satisfying the nutritional needs of humans. The tripes are an exception, but their consumption is now marginal, and could not contribute significantly to dietary improvements. Indeed, by adequate feeding of the animals, it is easily possible to change the nutritional value of eggs (mainly at the level of vitamins $A, D$ and $E$, and for some elements such as iodine) and fish (for vitamins $\mathrm{D}$ and $\mathrm{E}$, and many elements, particularly iodine, selenium and iron). $\mathrm{A}$ new approach is under investigation using micronutrients that are not indispensable for humans and are found in animal products destined for human consumption. An example are the liposoluble carotenoids. Among these, lutein and zeaxanthine are present in egg yolk and contribute to its colour. Interestingly, recent works have shown that the level of these substances in the egg can be increased by feeding laying hens an appropriate diet. A new find is that eating eggs enriched in this manner has increased the concentration of these two carotenoids in the blood of volunteers, and consequently in their retinas. This means that these substances already present in the eye, in particular in the retina, can be increased by lutein and zeaxanthine. It is well known that cataract and macular degeneration due to age are two-fold less frequent in subjects whose blood level of these substances is high compared to those with low blood levels. Other substances are on the horizon: for example the CLA's, which have many interesting properties, in particular their effect of increasing lean mass and decreasing fat mass. There is also perhaps also a new vitamin that as been described 
recently, vitamin PQQ (pirroloquinoline quinone), which would belong to the B group of vitamins. What is the effect on the price paid by the consumer? In fact, the additional cost is modest compared to the considerable gain in nutritional value. Thus, for an increase of $5 \%$ in the price per egg there is a tenfold increase in omega-3 levels, and consequently an almost equal decrease in the price per gram of omega-3. Results for fish should be similar [2]. In fact, rapeseed oil (canoal oil) is the best and the cheapest food to provide alpha-linolenic acid. Taken into account the important deficit in omega-3 fatty acids in the usual french food (the same is true in most developed countries), less than $50 \%$ of the recommended dietary allowances, il is obliged to promote foodstuff bringing daily, in usual serving, may decigrams of alpha-linolenic acid and \lor few hundred milligrams of $\mathrm{EPA}+\mathrm{DHA}$. The ratio omega-6\\omega-3 must be as close as possible of $5 \backslash$; saturated fatty acids must be minimized. In usual food, it is rapessed oil (canola oil) and wallnut oil, soyabean oil to a lesser extend, fatty fishes $\backslash$; and, if animals have been adequately fed, eggs and farmed fishes.

Mots-clés : alimentation animale, acides gras oméga-3, colza, poisson, œuf, CLA, caroténoïdes, valeur nutritionnelle, prix

Keywords : Animal feeding, omega-3 fatty acids, canola, rapessed, fish, egg, CLA, carotenoïds, nutritional value, cost

\section{ARTICLE}

Auteur(s) : Jean-Marie BOURRE

Membre de l'Académie de Médecine. Directeur de l'unité Inserm U26 de Neuro-pharmaco-nutrition, Hôpital Fernand-Widal, 200, rue du Faubourg-Saint-Denis, 75745 Paris Cedex 10.

Corresponding author: E-mail : jean-marie.bourre@fwidal.inserm.fr

Tél. : 0140054339

Fax : 0140344064

Reçu le 21/11/03

Accepté le 21/12/03

Plusieurs articles récents publiés dans $O C L$ ont attiré l'attention sur l'effet des acides gras polyinsaturés de la famille oméga-3 sur les structures cérébrales et leur fonctionnement [1-3], la neurotransmission et la cognition [4]. Par ailleurs, la question très intéressante a été posée de la concrétisation des perspectives concernant ces acides gras évoquées dans un congrès récent [5]. En outre, les apports nutritionnels, au moins pour ce qui concerne la population française de la région Aquitaine, sont insuffisants [6]. II est donc indispensable, d'une part de faire le point sur les aliments contenant des acides gras oméga-3, en quantités suffisantes pour participer significativement à la couverture des besoins journaliers en acides oméga-3 et, d'autre part, d'évaluer les possibilités d'enrichissement d'un certain nombre de produits par la sélection d'une alimentation animale 
pertinente. L'intérêt de l'acide oléique, conditionnellement essentiel pour certains organes, reste en suspens $[7,8]$. Par ailleurs, l'intérêt d'une classe d'acides gras particuliers, les CLA (conjugated linoleic acid), a été souligné dans le cadre des aliments fonctionnels [9]. D'autant que ces acides gras entrent précisément dans le cadre des "alicaments", dont les valorisations vont de la santé publique jusqu'au marketing [10].

Comme le montre cette synthèse, ce sont les lipides qui sont presque exclusivement concernés. Ils sont donc évoqués prioritairement dans cette introduction. En fait, les lipides, et plus particulièrement les acides gras oméga-3, ont constitué la première démonstration expérimentale cohérente de l'effet de substances alimentaires (les nutriments) sur la structure et la fonction du cerveau ; d'autant que, immédiatement derrière le tissu adipeux, le cerveau est l'organe le plus riche en lipides et en acides gras oméga-3, dont les seuls rôles sont de participer aux structures membranaires. Il a d'abord été découvert que la différenciation et la fonctionnalité de cultures cellulaires de cerveau dissocié nécessitent, non seulement l'acide alpha-linolénique (premier élément de la famille oméga-3), mais aussi les très longues chaînes carbonées oméga-3 et oméga-6 [11]. II a ensuite été démontré que la carence en acide alpha-linolénique altérait le cours du développement cérébral, perturbait la composition et la physicochimie des membranes des cellules cérébrales, neurones, oligodendrocytes et astrocytes [12]. Cette carence se traduit par des modifications physicochimiques, induisant des perturbations biochimiques, physiologiques et des perturbations neuro-sensorielles et comportementales [13]. En conséquence, la nature des acides gras polyinsaturés (en particulier oméga-3) trouvés dans les laits adaptés pour nourrissons (prématurés comme nés à terme) conditionne les capacités visuelles et cérébrales, y compris intellectuelles. Par ailleurs, les acides gras oméga-3 alimentaires sont évidemment impliqués dans la prévention de plusieurs facteurs des maladies cardiovasculaires, comme cela est démontré dans un grand nombre de travaux (notamment sur la vascularisation cérébrale), et de certaines affections neuropsychiatriques, dont la dépression, mais aussi la démence, notamment celle de la maladie d'Alzheimer (les résultats sont récents). Leur déficit peut empêcher le bon renouvellement des membranes et donc accélérer le vieillissement cérébral. En fait, compte tenu de la richesse du cerveau en acides gras poly-insaturés, il est logique qu'ils soient impliqués dans les maladies neuropsychiatriques et le vieillissement. La nomenclature des principaux acides gras est fournie dans la figure 1.

\section{Aliments participant à la couverture en acides gras poly-insaturés chez l'homme}

II ressort d'une étude réalisée récemment en Aquitaine que les femmes en âge d'être enceintes ou qui le sont absorbent dans leur alimentation $90 \%$ de l'acide linoléique dont elles ont besoin, mais seulement $40 \%$ de l'acide alpha-linolénique [6]. Des résultats analogues ont été publiés pour d'autres pays, comme le Canada [14] et la Suède [15]. Bien que les produits laitiers ne recèlent que de faibles quantités d'oméga-3, le fait qu'ils soient consommés en fortes quantités leur confère une place importante dans les apports. II en est de même des viandes (surtout mono-gastriques, de type porc, et des volailles). La part des huiles végétales (figure 2) reste étonnamment modeste, il est donc possible de recommander d'augmenter considérablement leur utilisation (principalement celle de colza), afin de couvrir les besoins recommandés. Les projets d'amélioration de la valeur nutritionnelle des aliments ont donc un intérêt qui est considérable pour certains. L'influence de ce que mangent les animaux, avant qu'ils ne se retrouvent sous forme de viande ou de tout autre produit dans une assiette, est attestée par les traditions culinaires des esquimaux : les 
viandes d'ours et d'autres mammifères (terrestres et marins) qui sont à leur disposition alimentaire sont riches en oméga-3, du fait même de l'alimentation spontanée de ces animaux. Cette observation constitue le cas naturel d'un carnivore dont la valeur nutritionnelle de la viande dépend de ce qu'il consomme ; ce qui justifie la possibilité de modifier le profil en acides gras des lipides, en donnant, par exemple, des graines de lin ou de colza à des animaux d'élevage. L'objet de cette synthèse est d'évaluer la contribution réelle à la couverture des besoins de la consommation par l'homme de produits animaux « naturellement enrichis » en acides gras oméga-3 par l'utilisation d'aliments riches en oméga-3 destiné aux animaux. Les aliments enrichis par addition finale d'acides gras oméga-3 (par exemple le lait enrichi en huile de poisson par addition de microgélules dans certaines boissons lactées, le pain enrichi en oméga-3, voire le pain composé avec des graines de lin) ne font pas l'objet de ce travail.

\section{Conséquences de l'alimentation animale sur les viandes et autres produits consommés par l'homme}

La nature des sols, et surtout les cultivars et les espèces, induisent des différences dans la composition des produits végétaux qui sont plus importantes que la méthode de culture elle-même. Par exemple, en termes de lipides, les différences de composition en acides gras poly-insaturés des huiles d'arachide d'origine africaine ou américaine sont importantes. II en est de même pour les huiles d'olive : une étude de diverses variétés d'oliviers cultivés en Tunisie [16] met en évidence des différences notables dans le contenu en acide oléique, linoléique et alpha-linolénique (figure 3). Globalement, plus que le mode de culture, c'est le choix de l'espèce qui conditionne une valeur nutritionnelle recherchée. En d'autres termes, des modifications de culture des oliviers modulent peu le profil en acides gras des olives, mais peuvent modifier considérablement les quantités récoltées.

\section{Modulations de la composition des lipides des viandes de mammifères}

II convient de faire une distinction pratique fondamentale entre d'une part les lipides de structures (génétiquement déterminés, principalement trouvés dans la bicouche lipidique des membranes biologiques) et d'autre part ceux de réserves (modulables). Parmi les lipides de structure des tissus et organes biologiques, il faut distinguer les lipides polaires (principalement les phospholipides), dont les variations quantitatives et qualitatives en raison de la nature de leurs acides gras constitutifs sont relativement peu dépendantes de l'alimentation, sauf carence atteignant toute la physiologie de l'animal. En effet, leur présence dans l'assemblage des membranes biologiques est largement sous contrôle génétique, car chaque membrane bénéficie d'un profil particulier en relation avec ses fonctions spécifiques.

En revanche, les lipides de réserve (lipides qualifiés de neutres, principalement les triglycérides), dont les quantités varient considérablement selon la situation anatomique, présentent des profils en acides gras qui dépendent évidemment de l'espèce, voire de la race, mais aussi notablement de l'alimentation de l'animal.

La distinction à faire entre animaux monogastriques et animaux polygastriques porte sur les activités hydrogénantes des bactéries intestinales. Les mécanismes physiologiques et biochimiques de la digestion induisent des modifications (parfois radicales), des nutriments, les graisses en premier lieu. C'est ainsi que, pour ce qui concerne les mammifères, les animaux monogastriques (cochon, cheval) 
doivent être examinés différemment des polygastriques (bovins, ovins, caprins). Par exemple, chez ces derniers, les bactéries du rumen hydrogènent les acides gras poly-insaturés des végétaux; de ce fait la viande des polygastriques est beaucoup moins riche en ces acides gras (plus de 2 fois moins) que la viande des monogastriques. Une étude montre que le pouvoir hydrogénant du rumen du mouton est relativement important, il touche les acides gras mono-insaturés et poly-insaturés ; les très longues chaînes poly-insaturées sont moins hydrogénées (figure 4) [17]. En d'autres termes, pour ce qui implique les quantités d'acides gras poly-insaturés, la viande porcine est incontestablement plus riche que la viande bovine. Par conséquent les tentatives d'enrichissement en acides gras poly-insaturés, par exemple en ajoutant dans l'alimentation des graines de lin [18], ou bien des produits de la mer ou encore certains de leurs succédanés, seront beaucoup plus efficaces avec le cochon et la volaille qu'avec le bœuf ou l'agneau.

Bien évidemment, si les acides gras poly-insaturés sont protégés des mécanismes d'hydrogénation par les micro-organismes du rumen, ils sont alors partiellement retrouvés dans les tissus et le lait des ruminants, ce qui a été vérifié chez la chèvre [19]. Mais la question est posée par certains de la pertinence "écologique " ou de "naturalité » de nourrir des vaches avec des gélules d'huile de poisson.

\section{Viande bovine et de porc}

Quelques exemples (tableaux 1 à 3 ) illustrent les possibilités d'enrichissement en acides gras oméga3 de diverses viandes consommées par l'homme en modifiant la nourriture donnée aux animaux.

Tableau 1. Effets de graines de lin, d'extraits de poisson sur la teneur en oméga-3 des muscles de diverses espèces : viande de porc (longissimus thoracis), pourcentage des acides gras [20].

\begin{tabular}{|c|c|c|}
\hline Lipides & Contrôle & Graines de lin \\
\hline 18:3w3 Lipides neutres & 1,10 & 7,90 \\
\hline 22:6w3 Lipides neutres & 0,07 & 0,06 \\
\hline 18:3w3 Lipides polaires & 0,5 & 6,3 \\
\hline 22:6w3 Lipides polaires & 0,3 & 0,2 \\
\hline
\end{tabular}

Tableau 2. Effets de graines de lin, d'extraits de poisson sur la teneur en oméga-3 des muscles de diverse espèces : viande charolaise (longissimus thoracis), pourcentage des acides gras [21].

\begin{tabular}{|c|c|c|c|c|}
\hline ipides & Contrôle & Lin & Poisson & Lin + poisson \\
\hline 8:3w3 Lipides neutres & 1 & 19 & 15 & 12 \\
\hline 8:3w3 Phospholipides & 2,1 & 4,3 & 2,4 & 3,5 \\
\hline 2:6w3 Phospholipides & 0,5 & 0,6 & 1,1 & 1,2 \\
\hline
\end{tabular}


Tableau 3. Effets de graines de lin, d'extraits de poisson sur la teneur en oméga-3 des muscles de diverses espèces : viande d'agneau (longissimus thoracis), pourcentage des acides gras [22, 23].

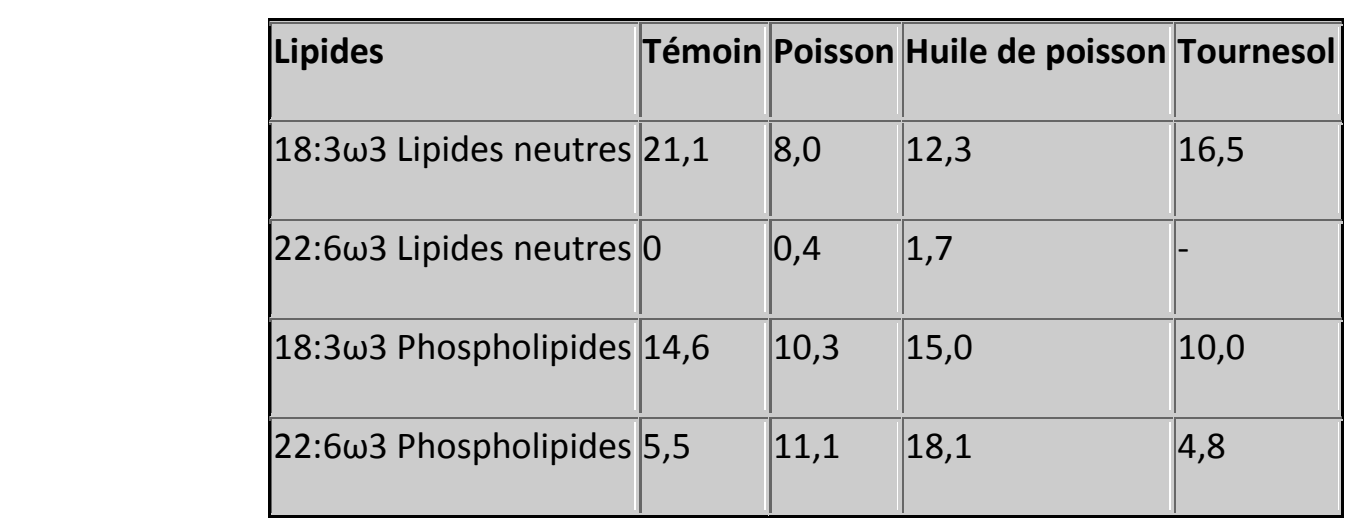

\section{Cas particulier du lait}

Outre les graines de lin [18] et de colza, il s'est avéré qu'incorporer des huiles de poisson (tableau 4) dans la nourriture des vaches constitue un moyen intéressant d'augmenter la teneur en EPA du lait [24].

Tableau 4. Composition du lait $(\mathrm{g} / \mathrm{kg})$ du lait de vache recevant de l'huile de poisson : en $\mathrm{g} / \mathrm{kg}$. D'après Keady et al. [24].

\begin{tabular}{|c|c|c|c|c|}
\hline Huile de poisson (g) par vache et par jour & 0 & 150 & 300 & 450 \\
\hline 18:3w3 Acide alpha-linoléique & 1,0 & 1,2 & 2,2 & 1,4 \\
\hline 20:5w3 Acide eicosapentaénoïque (EPA) & 0,7 & 1,0 & 1,5 & 5,3 \\
\hline 22:6w3 Acide cervonique (DHA) & 0,5 & 0,6 &, 2 & 1,7 \\
\hline
\end{tabular}

\section{Poissons}

Une multitude de publications ont démontré l'intérêt des acides gras oméga-3 issus de la chair de poisson dans le cadre, entre autres, de la prévention et du traitement de certains aspects des maladies cardiovasculaires, notamment obstructives. Il s'agit d'observations épidémiologiques, d'essais d'intervention chez les modèles animaux et chez l'homme. Afin de lutter contre l'hypertriglycéridémie, l'huile de chair de poisson a été un médicament remboursé par la sécurité sociale et reste un médicament de référence. Le rappel de cette volumineuse et démonstrative bibliographie ne peut malheureusement pas se situer dans le cadre de cette revue. Une série d'articles récents (dans les Cahiers de Nutrition et de Diététique daté de février 2003 et [160-163] plus loin dans cette revue) fait le point sur la variabilité de la qualité nutritionnelle des poissons, ainsi que de leur consommation et de leur perception sensorielle. Certes, il existe des variations importantes de composition selon les lieux de pêche, les saisons et bien d'autres paramètres ; mais il convient d'emblée de souligner que les différences sont encore plus importantes selon les formulations des aliments donnés aux poissons en élevage. La différence est d'autant plus spectaculaire qu'ils sont plus gras : selon la nature des graisses qui leurs sont données, la quantité 
d'acides gras oméga-3 dans leurs tissus (filets) peut varier considérablement, de plus de 1 à 20 . Maintes études ont certainement été réalisées par des centres techniques et des industriels orientés vers l'élevage des poissons, mais les données restent confidentielles, car elles ne sont souvent pas publiées dans des revues scientifiques ou médicales indexées dans les grandes banques de données mondiales (de type Medline). Les graisses, utilisées dans l'alimentation des poissons d'élevages, sont sélectionnées non pas en fonction de leur valeur nutritionnelle pour ces animaux, mais par rapport à leurs cours monétaires dans le monde. Pour des raisons de production de farines animales, ce sont les huiles de poisson qui sont actuellement utilisées, car peu onéreuses. Mais, dans un passé récent et dans un futur proche (notamment du fait de la contamination de ces huiles de poisson par les dioxines et les PCN), les huiles et graisses végétales seront à nouveau utilisées ; en particulier l'huile de palme et le coprah, ce qui est défavorable dans la perspective de l'alimentation humaine. Nourrir des truites avec de l'huile de hareng ou du lard (tableau 5) induit des différences importantes au niveau des acides gras oméga-3 [25]. Cet animal étant carnivore, il n'est que peu capable de transformer l'acide alpha-linolénique en chaînes plus longues, du fait de la réduction physiologique de l'activité de delta-6-désaturase. Ainsi, une alimentation contenant exclusivement de l'acide alphalinolénique (sans EPA ou DHA) n'assure quantitativement l'élaboration que de $5 \%$ du DHA, par rapport à une alimentation convenable [26]. Nourrir des saumons, non pas pendant leur vie entière, mais sur une période de 87 jours (tableau 6) avec de l'huile de colza ou du lard de porc fournit des teneurs identiques en 22:6w3 et en 20:5 $\omega 3$ dans les tissus du poisson, alors que l'huile de hareng permet d'obtenir des teneurs beaucoup plus importantes [27]. En fait, sur un plan économique et nutritionnel, après avoir nourri les poissons avec " n'importe quelle graisse " pendant un partie de leur existence, la question est de connaître la durée précédent leur abattage pendant laquelle il faut leur fournir une alimentation riche en DHA et EPA, afin que la composition de leur chair soit satisfaisante en termes de teneurs en acides gras oméga-3.

Tableau 5. Truites nourries avec des extraits de hareng ou de porc. D'après Hoffmann et al. [25]

\begin{tabular}{|l|l|l|}
\hline Acides gras & Hareng & Porc \\
\hline $20: 5 \omega 3$ & 2,2 & 0,5 \\
\hline $22: 5 \omega 3$ & 5,3 & 0,3 \\
\hline $22: 6 \omega 3$ & 1,7 & 0,5 \\
\hline
\end{tabular}

Tableau 6. Saumons nourris avec des huiles de hareng, de colza ou du lard de porc : pourcentage des acides gras. Alimentation pendant 87 jours, la température de l'eau étant de 10 à $12^{\circ} \mathrm{C}$. D'après Dosanjh et al. [27].

\begin{tabular}{|l|l|l|l|}
\hline Acides gras & Huile de harreng & Huile de colza & Lard de porc \\
\hline $18: 3 \omega 3$ & 1,0 & 3,3 & 0,8 \\
\hline $20: 5 \omega 3$ & 5,4 & 2,4 & 2,2 \\
\hline $22: 6 \omega 3$ & 14,0 & 7,3 & 7,9 \\
\hline
\end{tabular}


Avec le saumon (tableau 7) comme avec la truite, utiliser de l'huile d'olive ou bien de l'huile de tournesol riche en acide oléique ne permet pas d'atteindre les teneurs en acides gras oméga3 obtenues en nourrissant les animaux avec de l'huile de hareng [28].

Tableau 7. Saumons nourris avec de l'huile " oléique " ou de hareng: ( $g$ d'acides gras $/ 100 \mathrm{~g}$ de lipides). Muscle de saumon. D'après Skonberg et al. [28].

\begin{tabular}{|l|l|l|l|}
\hline Huile & $18: 3 \omega 3$ & $20: 5 \omega 3$ & $22: 6 \omega 3$ \\
\hline Oléique & 1,6 & 2,4 & 9,20 \\
\hline Hareng & 2,1 & 7,8 & 14,0 \\
\hline
\end{tabular}

Globalement, apporter dans l'alimentation des poissons des aliments de type graines de lin ou de colza sera efficace chez les poissons végétariens (comme la carpe), qui possèdent les équipements enzymatiques assurant la transformation de l'acide alpha-linolénique en chaînes carbonées plus longues et plus insaturées de type EPA et DHA. En revanche, un tel régime s'avère largement inefficace chez les poissons carnivores, dont les activités enzymatiques sont réduites, voire absentes (il en est de même pour les félidés, en ce qui concerne les animaux terrestres). Or, environ $75 \%$ des poissons sont carnivores obligatoires, ils ne sont alors que peu capables de transformer le 18:3 $\omega 3$ en

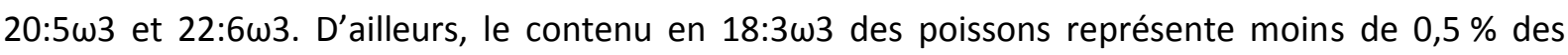
acides gras, ce qui est très faible [29]. De ce fait, la quantité de 22:6w3 dans la chair du poisson est directement fonction de celle de cet acide trouvée dans ses aliments (tableau 8) [30]. D'une manière générale, il est connu depuis de nombreuses années que les poissons d'élevage présentent un rapport oméga-3/oméga- 6 moins bon que celui trouvé chez les poissons sauvages : 2 contre 7 chez la truite, 2 contre 5 chez l'anguille, 6 contre 11 chez le saumon [31].

Tableau 8. Truites nourries avec deux quantités de lard ou de l'huile de hareng, en pourcentage des acides gras totaux. D'après Yu et al. [30].

\begin{tabular}{|c|c|c|c|}
\hline Acides gras & \multicolumn{3}{|c|}{$50 \%$ lard $33 \%$ lard $22 \%$ huile de hareng } \\
\hline 22:6w3 dans les aliments & 4,7 & 6,2 & 9,4 \\
\hline 22:6w3 dans la chair & 5,6 & 8,6 & 11,1 \\
\hline
\end{tabular}

\section{Volailles}

La physiologie digestive des oiseaux préserve relativement bien les acides gras poly-insaturés consommés par ces animaux (tableau 9). Dans les tissus de l'animal, un effet dose est observé (tableau 10), notamment pour ce qui concerne des teneurs en 18:3w3. Cet effet est moins net avec le 22:6w3, car de fortes teneurs alimentaires en graines de lin diminuent légèrement cet acide, alors que le 18:3w3 est augmenté. La volaille est donc considérée comme un excellent moyen de modifier favorablement le statut nutritionnel des Américains en oméga-3 [33]. Certains végétaux riches en 
acides gras oméga-3, notamment subtropicaux (chia), ont même été proposés pour nourrir les volailles et produire des viandes enrichies en acides gras oméga-3 [34].

Tableau 9. Teneur en oméga-3 dans les cuisses de poulet issues d'animaux nourris avec du maïs, des huiles de maïs, de lin ou de menhaden, en pourcentage des acides gras. 2,5\% dans l'alimentation. D'après Chanmugam et al. [32].

\begin{tabular}{|l|l|l|l|}
\hline Acides gras & Maïs & Lin & Menhaden \\
\hline $18: 3 \omega 3$ & 1,4 & 11,4 & 1,1 \\
\hline $22: 6 \omega 3$ & 0,2 & 0,4 & 1,4 \\
\hline
\end{tabular}

Tableau 10. Effet de quantités croissantes de graines de lin : en pourcentage des acides gras totaux.

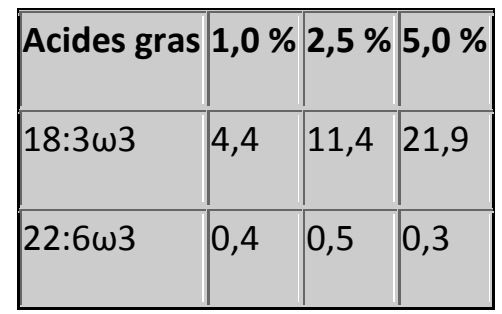

œufs, sources d'acide alpha-linolénique et de DHA pour l'homme

L'efficacité, prévisible, est encore plus spectaculaire au niveau des œufs, qui constituent en quelque sorte le modèle de valorisation alimentaire, car la nature des acides gras du jaune d'œuf est en relation importante avec la nature de graisses mangées par la poule (tableau 11)

Tableau 11. Composition des œufs selon la nourriture de la poule $(\mathrm{mg} / \mathrm{g}$ de jaune d'œuf). D'après Simopoulos et al. [35, 36]. Le "standard actuel " est qualifié d'« industriel " par les auteurs de ce travail.

\begin{tabular}{|c|c|c|c|}
\hline Acides gras & Standard actuel & Poissons & Graines de lin \\
\hline Saturés, dont : & 80,7 & 92,9 & 86,9 \\
\hline - palmitique (16:0) & 56,7 & 67,8 & 58,9 \\
\hline - stéarique (18:0) & 22,9 & 23,0 & 26,7 \\
\hline Mono-insaturés, dont : & 115,4 & 108,9 & 99,1 \\
\hline 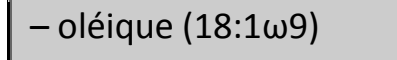 & 110,0 & 102,8 & 94,2 \\
\hline Poly-insaturés $\omega 6$, dont : & 33,9 & 74,1 & 46,0 \\
\hline - linoléique (18:3w6) & 26,1 & 67,8 & 42,4 \\
\hline
\end{tabular}




\begin{tabular}{|c|c|c|c|}
\hline Poly-insaturés $\omega 3$, dont : & 1,7 & 11,3 & 28,0 \\
\hline - alpha-linolénique (18:3w3) & 0,5 & 4,1 & 21,3 \\
\hline - DHA, cervonique (22:6w3) & 1,1 & 6,5 & 5,1 \\
\hline - Rapport $\omega 6 / \omega 3$ & 19,9 & 6,6 & 1,6 \\
\hline
\end{tabular}

Le rapport oméga-6/méga-3 des œufs grecs "sauvages " est de 1,3 exactement, alors qu'il est de 19,9 pour les œufs qualifiés d'« industriels » [35]. Une explication en est la consommation par les poules grecques de pourpier (une variété de salade), d'escargots et de limaces. L'enrichissement est proportionnel à la quantité d'acides gras oméga-3 présents dans l'alimentation de la poule. Il est plus important avec des graines de lin qu'avec des graines de colza (tableau 12)

Tableau 12. Effet de la présence de graines de lin ou de colza sur la composition en acides gras de I'œuf, en pourcentage des acides gras totaux. Jaune d'œuf, Canola: colza canadien et US, nouvelle variété ne contenant pas d'acide érucique. ; le même colza est cultivé en France. D'après Cherian et al. [37].

\begin{tabular}{|c|c|c|c|c|}
\hline Acides gras & Contrôle & Lin (8 \% graine) & Lin (16 \% graine) & Canola (16 \% graine) \\
\hline C18:3w3 & 0,62 & 5,79 & 8,76 & 2,37 \\
\hline C20:5w3 & 0,00 & 0,12 & 0,15 & 0,11 \\
\hline C22:5w3 & 0,00 & 0,29 & 0,30 & 0,18 \\
\hline C22:6w6 & 1,02 & 1,42 & 1,54 & 1,49 \\
\hline
\end{tabular}

Il y a une relation linéaire entre le contenu en acide alpha-linolénique dans les aliments (fourni par de l'huile de graines de lin ou de soja) et la teneur en cet acide gras dans le jaune de l'œuf, puis d'ailleurs aussi dans le cerveau et le sérum des poussins issus de ces œufs (tableau 13).

Tableau 13. Effet de la présence d'huile de poisson, de lin, de soja ou de carthame sur la composition des acides gras de l'œuf, en pourcentage des acides gras totaux (jaune d'œuf). D'après Anderson et al. [38].

\begin{tabular}{|l|l|l|l|l|l|}
\hline Acides gras & $\begin{array}{l}\text { Contrôle } \\
\mathbf{2 , 9} \%\end{array}$ & $\begin{array}{l}\text { Poisson } \\
(\mathbf{1 0 0} \mathrm{g}) \\
\text { Maxepa/kg }\end{array}$ & $\begin{array}{l}\text { Lin } \\
(\mathbf{1 0 0} \mathrm{g} / \mathrm{kg})\end{array}$ & $\begin{array}{l}\text { Soja-huile } \\
(\mathbf{1 0 0} \mathrm{g} / \mathrm{kg})\end{array}$ & $\begin{array}{l}\text { Carthame } \\
(\mathbf{1 0 0} \mathrm{g} / \mathrm{kg})\end{array}$ \\
\hline $16: 0$ & 26,1 & 27,1 & 18,7 & 22,4 & 24,0 \\
\hline $18: 0$ & 9,5 & 10,7 & 12,5 & 11,3 & 10,8 \\
\hline
\end{tabular}




\begin{tabular}{|c|c|c|c|c|c|}
\hline Total saturés & 36,3 & 39,2 & 31,9 & 34,0 & 34,9 \\
\hline $18: 1 \omega 9$ & 40,3 & 35,6 & 33,0 & 33,1 & 25,0 \\
\hline $\begin{array}{ll}\text { Total mono- } \\
\text { insaturés }\end{array}$ & 44,4 & 39,9 & 35,0 & 35,2 & 27,7 \\
\hline $18: 2 \omega 6$ & 14,7 & 8,2 & 17,5 & 23,4 & 30,0 \\
\hline $20: 4 \omega 6$ & 2,1 & 0,7 & 1,4 & 2,1 & 3,2 \\
\hline $22: 5 \omega 6$ & 0,5 & 0,08 & - & - & 0,9 \\
\hline Total w6 & 17,8 & 9,6 & 19,7 & 25,2 & 35,9 \\
\hline $18: 3 \omega 3$ & 0,4 & 0,4 & 9,4 & 1,7 & 0,06 \\
\hline $20: 5 \omega 3$ & - & 2,1 & 0,3 & - & - \\
\hline 22:6w3 & 0,6 & 6,3 & 2,2 & 1,8 & 0,2 \\
\hline Total $\omega 3$ & 10 & 10,1 & 12,6 & 3,1 & 0,3 \\
\hline Total $\omega 6+\omega 3$ & 18,8 & 19,7 & 32,3 & 28,3 & 36,2 \\
\hline$\omega 6 / \omega 3$ & 17,8 & 1,0 & 1,6 & 8,1 & 120 \\
\hline
\end{tabular}

Les effets des acides gras oméga-3 des œufs ont été évalués à travers des études de paramètres physiologiques chez l'animal pour extrapolation à l'homme. Il s'est agi de déterminer les effets au niveau de paramètres physiologiques lipidiques $[39,40]$ ou bien au niveau de la construction et du fonctionnement des membranes biologiques, surtout cérébrales [41-44]. La consommation de ces œufs par l'homme induit des effets favorables, en particulier au niveau des paramètres biologiques lipidiques. Un premier travail a porté sur des hommes et des femmes recevant par jour pendant 4 semaines soit 4 œufs oméga-3, soit 4 œufs standard du commerce. La concentration plasmatique (sanguine) de cholestérol est augmentée chez ceux qui consomment des œufs du commerce, mais pas chez ceux qui utilisent les œufs oméga-3. La teneur plasmatique en triglycérides est diminuée avec les œufs oméga-3, mais augmentée avec les œufs standard. De plus, les pressions sanguines systolique et diastolique sont diminuées avec les œufs oméga-3, alors que les œufs standard ne modifient pas ces paramètres [45]. Un deuxième travail [46] a globalement confirmé ces résultats.

Un troisième travail [47] a tout d'abord mesuré les effets de quantités variables d'acide alphalinolénique dans l'alimentation des poules sur la composition de leurs œufs. Ainsi, une alimentation contenant $0 \%, 10 \%$ et $20 \%$ d'huile de graines de lin induit une augmentation de l'acide alphalinolénique des œufs (28, 261 et 527 milligrammes par œuf) et du DHA (51, 81 et 87 milligrammes par œuf), tout en ne modifiant pas la concentration du cholestérol dans les œufs. L'essai a porté sur 28 hommes, mangeant 4 œufs par jour. II n'a pas été observé de différence significative au niveau de 
leur cholestérol total, du cholestérol-HDL (le « bon » cholestérol), ni de la teneur plasmatique en triglycérides. En revanche, il a été trouvé une augmentation des acides gras oméga-3 et du DHA et une diminution du rapport oméga-6/oméga-3 dans les phospholipides des plaquettes des sujets consommant des œufs oméga-3. Cette étude conclut que les œufs constituent un aliment très intéressant, pour répondre aux prescriptions gouvernementales (canadiennes en l'occurrence) et assurer une l'augmentation de la consommation d'acides gras oméga-3. Les œufs enrichis en oméga-3 modulent le profil lipidique sanguin chez les patients hypercholestérolémiques, induisant une légère augmentation du cholestérol, mais une diminution importante des triglycérides [48]. Les effets cliniques des œufs enrichis en oméga-3 sont donc positifs [49]. Bien que les œufs apportent du cholestérol en quantités importantes, la présence des acides gras oméga-3 s'avère utile dans le cadre de la lutte contre les maladies cardiovasculaires. En alimentation infantile [36], il convient impérativement de noter que des extraits de jaune d'œuf (issus de poules nourries avec des aliments judicieusement choisis) sont ajoutés par quelques marques de laits adaptés pour nourrisson et, de ce fait, que ce lait présente l'avantage d'apporter les mêmes quantités d'acides gras à très longues chaînes - notamment les acides gras oméga-3 - que le lait de femme [50-53]. Les acides gras du plasma sanguin et des globules rouges sont identiques chez les enfants nourris au sein et chez ceux recevant un lait adapté contenant des extraits de jaune d'œuf enrichi en acides gras oméga-3 [54]. Le lait de femmes consommant des œufs enrichis en acides gras oméga-3 contient de plus grandes quantités de ces acides [55].

\section{Alimentation des animaux destinés à être mangés par d'autres animaux (problème dans les zoos)}

La valeur nutritionnelle d'animaux vivants (ou morts) contribuant à l'alimentation d'autres animaux en captivité pose des problèmes, dans la mesure ou leur qualité nutritionnelle peut être mise en cause. Ainsi, la nature des acides gras des souris destinées à nourrir d'autres animaux est à prendre en compte [56].

\section{Incidences sur le goût de l'aliment final absorbé par l'homme}

Les lipides sont principalement concernés, car ils participent directement à la flaveur des aliments. Ils sont en relation directe avec la qualité de la viande, notamment les phospholipides constituent les principaux générateurs de flaveur [57]. La nature des acides gras poly-insaturés de la viande de bœuf a une incidence sur son goût, à travers l'élaboration de composés volatiles lors de la cuisson, outre la réaction de Maillard [58]. Des substances particulières (2-alkyl-thiapyrans et 2-alkylthiophènes) ont été identifiées dans la viande cuite de bœuf et de mouton [59].

Concernant les volailles, l'utilisation de graines de lin ou d'huile de menhaden (un poisson) modifie le goût de la viande [60]. En revanche une étude portant sur la viande de porc enrichie ( $2 \%$ en huile de poisson et $1 \%$ en huile de colza) montre que l'augmentation des teneurs en acides gras oméga- 3 ne modifie pas la couleur ni le goût [61]. Au contraire, de fortes quantités de graines de lin (15\% de l'alimentation) modifient le goût de la viande : l'intensité est plus forte, mais les défauts de goût plus fréquents $[62,63]$. En ce qui concerne les œufs, nourrir des poules pondeuses avec de l'huile de menhaden n'induit pas de modification notable du goût [64]. Toutefois, il est signalé que de fortes concentrations d'huile de poisson dans l'alimentation des poulets peuvent induire des altérations des flaveurs. 
Les protéines données à l'animal induisent des modulations quantitatives, mais non qualitatives, de l'aliment consommé par l'homme

Bien que le muscle contienne des quantités importantes de protéines, leurs compositions, c'est-àdire leurs profils en acides aminés, sont sous contrôle génétique. Pour une espèce donnée (et même une race), les modifications de l'alimentation des animaux peuvent induire des évolutions quantitatives au niveau des protéines, mais peu d'améliorations qualitatives. En d'autres termes, il est possible, par la sélection, de faire produire à l'animal plus de muscle, donc plus de protéines de qualité, mais leurs valeurs biologiques resteront les mêmes. À l'exception du lait, toute manipulation génétique susceptible d'enrichir en tel ou tel acide aminé indispensable est probablement illusoire. En effet, elle aboutirait à la synthèse d'une protéine dont la fonctionnalité pourrait être atteinte, ce qui est incompatible avec une physiologie normale, donc avec un fonctionnement musculaire harmonieux ; l'intérêt économique d'une telle manipulation serait donc amoindri. En revanche, en ce qui concerne le lait, des animaux transgéniques peuvent synthétiser des substances diverses, y compris des médicaments. Il est donc logique de pouvoir proposer d'améliorer, par exemple, la valeur nutritionnelle des protéines du lait ; mais celle-ci est déjà excellente. Les besoins globaux en protéines, et spécifiques en leurs acides aminés indispensables, varient selon les espèces animales. Ainsi, ceux des poissons sont considérables. La digestibilité des protéines chez le jeune cochon est améliorée par la présence dans les aliments d'huile de colza [65], ce qui est par ailleurs intéressant sur le plan lipidique, preuve de l'inter-relation entre les nutriments. Inversement, il a été vérifié que l'addition d'huile de lin dans l'alimentation des poulets (dans le but d'améliorer la valeur nutritionnelle au niveau des lipides) ne modifie pas le dépôt des acides aminés dans le muscle [66].

\section{Les glucides : impact faible du glycogène animal en nutrition humaine}

Quantitativement, en termes de stockage de réserve d'énergie, les glucides n'existent dans le monde animal pratiquement que sous la forme de glycogène, qui constitue une partie très marginale de l'apport en glucides dans la ration alimentaire de l'homme. Lors de la maturation des viandes avant leur mise sur le marché, une partie de ce glycogène est perdue. L'apport glucidique relève de préoccupations vétérinaires et zootechniques, afin de permettre une bonne croissance de l'animal, compte tenu de ses spécificités. La nature des glucides complexes est donc à prendre en compte, mais seulement au strict niveau du besoin de l'animal.

\section{Les minéraux, oligo-éléments et vitamines : sauf exceptions, peu de modifications chez l'animal, donc faibles conséquences chez l'homme qui consomme ses produits}

En termes de physiologie générale, les vitamines et les minéraux participent à des mécanismes parfaitement régulés, qui nécessitent des quantités bien précises. De ce fait, normalement, un accroissement quantitatif de ces nutriments dans l'alimentation animale ne se traduit pas par une augmentation notable dans leurs tissus, sauf ceux de stockage. Globalement donc, toute déviation nutritionnelle en vitamine et minéraux chez l'animal induit des problèmes vétérinaires et zootechniques qui alertent les éleveurs, mais restent sans implication directe sur la valeur des produits dérivés retrouvés dans l'alimentation du consommateur. Toutefois, les teneurs en vitamines ( $A, D$ et $E$ ) et minéraux (notamment en iode) des œufs peuvent être grandement améliorées par une alimentation adaptée des poules pondeuses. En effet, leurs teneurs en vitamines sont en relation avec les quantités de ces vitamines absorbées par les poules pondeuses, avec parfois des compétitions: la présence de multiples caroténoïdes diminue la quantité de l'un d'entre eux, le 
bêtacarotène, seul précurseur de la vitamine $A$; en d'autres termes, l'intensité de la couleur jaune n'implique pas une présence importante de bêtacarotène. Par ailleurs, chez le poisson $[67,160]$, il a été mis en évidence une différence importante dans les teneurs en certains minéraux entre les poissons d'élevage et sauvages (tableau 14). Globalement, pour ce qui concerne les poissons, les teneurs en iode varient en fonction de la salinité des mers, c'est-à-dire d'une manière importante, pouvant aller du simple au double ; la teneur en sélénium dans leur chair est très dépendante de la concentration en sélénium de l'eau dans laquelle ils vivent. Le muscle rouge du poisson est beaucoup plus riche en fer que le muscle blanc ; les quantités peuvent être équivalentes, voire supérieures, à celles de la viande bovine, dans certaines espèces comme le thon ou le maquereau. Mais, pour une même espèce, les modalités d'élevage peuvent certainement impliquer des variations importantes des teneurs en fer. Du fait de leur consommation de krill, les poissons antarctique contiennent 5 fois plus de fluor que leurs congénères vivant ailleurs. Toutes ces observations sont évidemment à prendre en compte dans les formulations des aliments destinés aux poissons.

Tableau 14. Teneurs en certains minéraux entre poissons sauvages et d'élevage : flétan $(\mathrm{mg} / 100 \mathrm{~g})$. D’après Haard et al. [67].

\begin{tabular}{|l|l|l|}
\hline Mineraux & Sauvage & De ferme \\
\hline K & 635 & 644 \\
\hline $\mathrm{P}$ & 259 & 256 \\
\hline $\mathrm{Mg}$ & 35 & 35 \\
\hline $\mathrm{Ca}$ & 10 & 13 \\
\hline $\mathrm{Na}$ & 58 & 60 \\
\hline $\mathrm{Fe}$ & 0,378 & 1,660 \\
\hline $\mathrm{Zn}$ & 0,369 & 0,404 \\
\hline $\mathrm{Cu}$ & 0,033 & 0,046 \\
\hline
\end{tabular}

La vitamine $D$ constitue une cible intéressante pour enrichir certaines espèces, en particulier le poisson. Le risque toxicologique d'une surdose de vitamine $\mathrm{D}$ n'est pas la conséquence de l'utilisation de produits animaux (exception faite de l'utilisation abusive d'huile de foie de poisson, riche en vitamines $A$ et $D$, au contraire de l'huile de chair de poisson) et plutôt de traitements médicamenteux excessifs.

Les organes « enrichissables » chez les mammifères (mais aussi chez les poissons et les oiseaux) sont les produits tripiers, le foie en premier lieu, mais aussi les reins (c'est-à-dire les rognons). Leur consommation s'est considérablement réduite, elle est devenue minuscule à la suite de la crise de l'encéphalite spongiforme bovine (ESB). Bien que naturellement très riches, ils ne participent donc plus à l'équilibre alimentaire en termes de santé publique (chaque français consomme en moyenne moins d'une seule tranche de foie de veau par an). La valorisation du foie de volaille mériterait un 
effort ; sachant qu'un produit particulier, le foie gras, ne représente qu'une consommation marginale et coûteuse, que ce produit est gras, ce qui doit nécessairement limiter sa consommation humaine. En pratique, les élevages actuels n'utilisent plus systématiquement les grains de maïs (riche en acide oléique et contenant une petite quantité d'acide alpha-linolénique), mais d'autres graisses, dont le niveau de saturation se retrouvera dans les foies, ce qui n'est pas favorable. Une mention particulière concerne la vitamine $A$, dont les trop grandes quantités dans le foie de bovins, du fait des supplémentations vétérinaires, a écarté un temps cet aliment de la consommation humaine, en particulier chez les femmes enceintes. Le risque toxicologique de la vitamine $A$ fut réel. Ce problème est devenu beaucoup moins aigu pour deux raisons principales: d'une part la diminution des doses de vitamine $\mathrm{A}$ utilisées en alimentation animale, et d'autre part la réduction considérable de la consommation humaine de foies d'animaux (les seules populations exposées restent celles ayant une alimentation particulière, très carnivores et friandes d'abats, comme les esquimaux).

La vitamine $\mathrm{E}$ constitue un nutriment particulier. Le terme de vitamine $\mathrm{E}$ compte diverses formes chimiques. Mais seul l'alpha-tocophérol est présent dans les membranes biologiques, notamment cérébrales $[68,69]$. Sa concentration peut être augmentée dans la viande avec deux objectifs majeurs : le premier est d'améliorer la valeur nutritionnelle de celle-ci, le second est de la protéger contre les oxydations, c'est-à-dire les rancissements. Pour les œufs, l'enrichissement en vitamine $\mathrm{E}$ est doublement intéressant dans le même esprit [69]. La diminution de production de résidus d'oxydation a été mesurée dans la viande cuite de porc supplémenté en vitamine E [70]. Chez le porc, la supplémentation en tocophérol diminue le MDA sur la viande de cochon congelée pendant 4 mois à $-80^{\circ} \mathrm{C}$, mais pas sur celui conservé 10 mois à $-20^{\circ} \mathrm{C}$ [71]. La présence de vitamine $\mathrm{E}$ assure une meilleure conservation des filets de poisson [72].

Finalement, la concentration d'alpha et de gamma-tocophérol dans le sang de patients modérément hyperlipidémiques dépend de la nature des graisses consommées concomitamment, le gammatocophérol étant en particulier diminué par la présence de graisses saturées [72, 73]. En fait, de multiples essais ont été réalisés pour augmenter les acides gras poly-insaturés des produits animaux, du fait de leur fragilité, des anti-oxydants sont généralement simultanément ajoutés.

\section{Nouvelles voies : les micronutriments non indispensables pour l'homme, les caroténoïdes}

Les caroténoïdes constituent une famille d'environ 500 molécules, principalement formées de pigments solubles dans les lipides (c'est-à-dire liposolubles, dissous dans les graisses). Ils génèrent un nombre immense de couleurs que l'on rencontre dans la nature. Ils participent aux multiples colorations des oiseaux [74]. Parmi ces caroténoïdes, 24 environ sont trouvés dans le sang et les tissus humains et seulement 2 dans les yeux, au niveau de la rétine. Ceux qui ont été les plus étudiés sont le bêtacarotène, le lycopène, la lutéine et la zéaxanthine. Le bêtacarotène appartient à la classe des carotènes, qui sont particulièrement liposolubles; il est reconnu comme précurseur de la vitamine $A$, mais d'autres rôles qui lui sont propres sont certainement importants. Le lycopène, présent en grande quantité dans la tomate, a été très étudié dans le cadre de la prévention de certains cancers, notamment celui de la prostate. La lutéine et la zéaxanthine appartiennent à une sous-famille des caroténoïdes dénommée xanthophyles; comme ils possèdent au moins un groupe hydroxyl, ils sont chimiquement plus polaires que les carotènes. La lutéine et la zéaxanthine ne sont pas transformées en vitamine $A$, contrairement au bêtacarotène, un autre caroténoïde. En fait, parmi la cinquantaine de caroténoïdes qui peuvent être transformés en vitamine $A$, le bêtacarotène est 
celui qui possède la plus grande activité provitaminique [75]. La lutéine contribue pour $70 \%$ à la coloration des œufs, même si une vingtaine d'autres caroténoïdes sont aussi présents [76]. Entre diverses sources végétales, l'utilisation d'algue dans la nourriture des poules pondeuses a même été évoquée [77]. En ce qui concerne les quantités de lutéine et de zéaxanthine, l'œuf se situe à la charnière entre le végétal et l'animal (tableau 15). En effet, ces substances sont présentes presque exclusivement dans le monde végétal en quantités, l'œuf faisant donc exception dans le monde animal.

Tableau 15. Lutéine et zéaxanthine dans quelques aliments. D’après Johnson et al. [78].

\begin{tabular}{|l|l|}
\hline Aliments & Contenu (mg/100 g) \\
\hline Choux-fleur & 15,8 \\
\hline Epinard cru & 7,1 \\
\hline Epinard cuit & 2,6 \\
\hline Laitue & 2,2 \\
\hline Brocoli cuit & 1,8 \\
\hline Maïs doux cuit & 1,4 \\
\hline Petit pois cuit & 0,3 \\
\hline Choux de Bruxelles cuit & 1,3 \\
\hline Choux vert & 0,3 \\
\hline
\end{tabular}

L'intérêt biologique de la lutéine et la zéaxanthine réside dans le fait que ces substances sont abondantes dans le jaune de l'œuf d'une part et, d'autre part s'accumulent dans la région maculaire de la rétine (région centrale de la rétine, le centre étant lui-même dénommé fovéa ; elle permet la vision des couleurs et celle des détails), où elles participent à l'efficacité de la vision. Elles sont en particulier liées à la tubuline de la rétine. La lutéine et la zéaxanthine pourraient donc prévenir la dégénérescence maculaire, une maladie qui menace, en France, 1,2 million de personnes de plus de 50 ans, s'avère aussi la première cause de cécité (définie comme étant une acuité visuelle inférieure ou égale à $1 / 20$ dans le meilleur œil). Or, actuellement, cette maladie est pratiquement incurable ; les stratégies de prévention sont donc très importantes, afin d'en prévenir les dommages. Anatomiquement, en allant vers la périphérie de la rétine, la concentration en zéaxanthine décline rapidement, tandis que celle de la lutéine décroît plus progressivement. Ces substances se retrouvent aussi présentes dans le cristallin [78]. L'un des rôles de la lutéine et de la zéaxanthine est de rendre meilleure la représentation visuelle, en particulier par protection contre les rayons UV et par filtration de la lumière bleue, qui est nuisible à la structure et donc à l'activité des 
photorécepteurs visuels, et d'ailleurs aussi à l'épithélium pigmentaire de la rétine. Le rôle d'antioxydant est certainement important, d'autant que la rétine et le cristallin sont soumis à un stress oxydatif notable, conséquence de la présence simultanée de lumière (qui favorise la formation d'espèces radicalaires) et d'oxygène, comme en témoigne, par exemple, leur grande vascularisation. La lutéine et la zéaxanthine constituent de meilleurs anti-oxydants que l'alpha et le bêtacarotène, tout au moins dans des liposomes [79]. De multiples produits d'oxydation de la lutéine et de la zéaxanthine ont été identifiés dans la rétine humaine, dont certains pourraient être impliqués dans la prévention de la dégénérescence liée à l'âge [80].

Toutefois, les teneurs en lutéine et en zéaxanthine sont relativement variables selon les œufs : une étude montre que la fourchette se situe du simple au double pour la lutéine et du simple au triple pour la zéaxanthine [81]. Point de grande importance, l'œuf est l'aliment le plus riche en lutéine et en zéaxanthine par rapport à son contenu total en caroténoïdes : à eux deux ils représentent un pourcentage molaire de 89 . En ce qui concerne la lutéine, l'œuf est en deuxième position (54 \% molaire) derrière seulement le maïs (60\%) mais devant le kiwi, les épinards, la courgette (environ $40 \%$ ) et le brocoli, le jus d'orange, le raisin, le choux de Bruxelles et la pomme (environ $20 \%$ ). Pour ce qui est de la zéaxanthine, l'œuf est en première position (35\%) devant le maïs ( $25 \%$ ), l'orange, la mangue (environ $20 \%$ ) [82].

Point très important, l'œuf contient moins de lutéine et de zéaxanthine que les végétaux, mais la biodisponibibité de ces dernières y est beaucoup plus grande [81]. En effet, la bio-disponibilité (c'està-dire le niveau de captation par l'intestin, se traduisant par une concentration dans le sang) des caroténoïdes est fonction de l'environnement alimentaire avec lequel ils sont absorbés. Des études ont montré que l'association de lipides augmente de manière notable la biodisponibilité de la lutéine et de la zéaxanthine. Par ailleurs, la localisation dans la structure de la plante (le chloroplaste ou le chromoplaste) interfère avec la formation de micelles dans l'intestin (par exemple avec la pectine), diminuant cette biodisponibilité ; cette réduction est partiellement levée par la cuisson. Cela n'est évidemment pas observé avec l'œuf. D'autant que la matrice lipidique du jaune, avec le cholestérol (200 mg/jaune), les triglycérides (4 g/jaune) et les phospholipides $(1 \mathrm{~g} / \mathrm{jaune})$, associée à des vitamines liposolubles (vitamine A, E et D) augmente la biodisponibilité de la lutéine et de la zéaxanthine [76]. Des essais cliniques chez l'homme ont montré que les patients inclus dans le groupe présentant la plus haute concentration en lutéine et en zéaxanthine bénéficie du risque le plus réduit en dégénérescence maculaire (Eye Disease Case-control Study Group ou EDCC, 1993). Or, une étude a également montré chez des volontaires humains que la supplémentation avec de la lutéine (à raison de $30 \mathrm{mg} / \mathrm{j}$, pendant 140 jours) augmente la concentration de lutéine dans le plasma sanguin et, concomitamment, dans la macula de l'œil humain [83]. En pratique, les personnes situées dans le quintile de la plus grande absorption de caroténoïdes présentent un risque de dégénérescence maculaire réduit de $45 \%$; ceux qui ont la plus grande absorption de lutéine et de zéaxanthine présentent un risque réduit de $57 \%$, l'effet étant indépendant de celui des autres caroténoïdes [84]. Dans cette étude, ceux dont la consommation en épinards est la plus importante ont un risque réduit de $86 \%$, les autres légumes étant moins efficaces (brocoli, choux, carotte, pomme de terre, courge). Toutefois, utiliser des épinards ou du maïs, qui apportent environ $300 \mu \mathrm{g}$ de zéaxanthine mais pas de lutéine, ne modifie pas la concentration plasmatique de ces composés [81].

En utilisant des œufs enrichis, c'est-à-dire des designer eggs, utilisés par ailleurs pour assurer un enrichissement en acides gras oméga-3, l'augmentation plasmatique de la lutéine est notable : elle 
est multipliée par deux, avec un contenu dans l'œuf multiplié par quinze étant noté que la cuisson ne modifie pas la quantité de lutéine dans les œufs [85]. Un autre essai clinique chez l'homme a montré que la supplémentation en lutéine ( $30 \mathrm{mg} / \mathrm{j}$ pendant 140 jours) se traduit par une augmentation de la densité optique des pigments de la macula de $21 \%$ et une diminution de la lumière bleue atteignant la rétine de 30 à $40 \%$, ce qui est tout à fait favorable [83].

Une étude mérite d'être détaillée. Onze hommes et femmes légèrement hyper-cholestérolémiques ont reçu un régime contenant $29-33 \%$ d'énergie sous forme de lipides, dont $20 \%$ sous forme d'huile de maïs ou de suif de bœuf. Ces alimentations ont été supplémentées avec du jaune d'œuf cuit (1,3 jaunes/jour/personnes) pendant 4 semaines. La supplémentation avec le suif de bœuf augmente la lutéine plasmatique de $28 \%$ et la zéaxanthine de $142 \%$; les augmentations en présence d'huile de maïs sont de $50 \%$ et $114 \%$ (tableau 16). La concentration du LDL-cholestérol est légèrement augmentée, de 8 à $11 \%$ [81]. Ces résultats sont obtenus avec des œufs standard. En utilisant des œufs enrichis, les résultats seraient très probablement meilleurs.

Tableau 16. Caroténoïdes plasmatiques $(\mu \mathrm{mol} / \mathrm{L})$ après supplémentation avec un jaune d'œuf. D'après Handelman et al. [81].

\begin{tabular}{|l|l|l|l|l|}
\hline Caroténoïdes & \multicolumn{2}{|l|}{ Huile de maïs } & \multicolumn{2}{l|}{ Suif de bœuf } \\
\cline { 2 - 5 } & seule & + œuf & seul & + œuf \\
\hline Lutéine & 0,269 & 0,403 & 0,333 & 0,427 \\
\hline Zéxanthine & 0,049 & 0,105 & 0,048 & 0,116 \\
\hline Lycopène & 0,390 & 0,392 & 0,325 & 0,420 \\
\hline Bêtacarotène & 0,642 & 0,691 & 0,538 & 0,696 \\
\hline
\end{tabular}

Il semble donc que l'utilisation non parcimonieuse d'œufs, de brocolis et d'épinards soit associée à la diminution du risque de cataracte (jusqu'à $20 \%$ ) et de celui de dégénérescence maculaire liée à l'âge (jusqu'à $40 \%$ ). Huit études épidémiologiques ont analysé la relation entre la cataracte et le taux de lutéine dans le sang et l'alimentation, 7 pour ce qui concerne la dégénérescence maculaire liée à l'âge [86].

\section{Une nouvelle « vitamine » : la pyrroloquinoline quinone}

La pyrroloquinoline quinone ( $P Q Q$ ) est présente dans le monde végétal, mais aussi dans les viandes. La question se posera dans un délai plus ou moins bref de son dosage précis dans les divers morceaux et de l'opportunité ou de la possibilité d'enrichissement dans les produits consommés par I'homme à travers la nourriture donnée aux animaux. Sur le plan de son rôle physiologique, cette vitamine est proche des vitamines B2 et B3. Chez le mammifère, en l'occurrence chez la souris, il a été très récemment découvert qu'il existe une réductase dépendante de la $P Q Q$, participant à la dégradation d'un acide aminé indispensable, la lysine [87]. Chez le mammifère, cela constitue la première démonstration du caractère vitaminique de la $P Q Q$. 
Présent dans les aliments, la PQQ est captée par l'organisme des mammifères. En effet, elle est rapidement absorbée dans l'intestin, au moins chez la jeune souris [88] et des traces sont trouvées dans divers tissus et dans le lait.

\section{Des molécules d'avenir : les acides linoléiques conjugués ?}

Une question fondamentale est posée quant à l'intérêt des acides linoléiques conjugués : s'agit-il de nutriment fonctionnels ? [9]. Il pourrait s'agir de la deuxième classe de substances du monde animal (après les acides gras oméga-3) présentant un effet physiologique, utilisable par lui-même avec plus d'amplitude par la pharmacologie. Elle est référencée sous l'acronyme de CLA (conjugated linoleic acid). Les études sur l'homme ou les essais zootechniques sur l'animal pour améliorer sa croissance ou sa valeur nutritive ne représentent qu'une fraction (18\%) des travaux qui lui sont consacrés. La plupart des recherches médicales et scientifiques, sur divers modèles, sont expérimentales et cognitives.

L'intérêt des CLA a été ciblé sur ce qu'il est convenu d'appeler le syndrome métabolique $X$, de par ses effets anti-athérogène, anti-diabétogène, anti-allergique, immunomodulateur, accroissant la croissance osseuse et surtout modulateur de la composition corporelle (effet intéressant d'augmentation de la masse maigre et de diminution de la masse grasse). Les CLA sont constitués d'un mélange d'acides octadécane-diènoiques. Ce sont des dérivés de l'acide linoléique [89]. On dénombre 28 isomères référencés, sans compter les métabolites, soit par allongement de la chaîne carbonée, soit par raccourcissement. En pratique, les deux seuls qui seraient biologiquement actifs sont le cis-9, trans-11 et le trans-10, cis-12 (figure 5). La découverte initiale fut d'isoler des composés anti-carcinogènes dans la viande de bœuf [90, 91], lesquels furent identifiés comme étant les $\operatorname{CLA}[92,93]$. Leur pouvoir anti-carcinogénétique fut ensuite retrouvé chez le rat, la souris et les cellules humaines [92-97]. L'isomère cis-9 trans-11 est réputé être le plus important, car il est le seul qui soit incorporé dans les phospholipides de rat quand ces animaux sont nourris avec un mélange d'isomères [98].

\section{Modes de formation}

Une fraction de la formation des CLA (figure 6) dans le rumen constitue la conséquence de l'attaque par les radicaux libres de l'acide linoléique, qui est aussi oxydé [92, 93]. Toutefois, historiquement, il a été montré dès 1967 que la bio-hydrogénation de l'acide linoléique par des bactéries du rumen (Butyrivibrio fibrisolvens) produit le 18:2 (9-cis 11-trans) [99]. Les enzymes des microorganismes du rumen réalisent une biohydrogénation des acides linoléique et alpha-linolénique, produisant de l'acide stéarique ; cette opération génère des intermédiaires et des sous-produits, parmi lesquels plusieurs isomères possédant une ou deux doubles liaisons, dont les CLA [92, 100-103]. Globalement, la biohydrogénation in vitro par les microorganismes induit la formation de plusieurs isomères de position trans-monoènes, plutôt que la formation d'acide stéarique, comme précédemment postulé [104].

La capacité des microorganismes à synthétiser les CLA a aussi été démontrée chez le rat. Toutefois, chez le rat germ-free, les concentrations des CLA ne sont pas modifiées par l'alimentation [102], montrant que la synthèse par les tissus est possible, indépendamment de la présence de microorganismes dans le tube digestif. Chez le castor, la présence de diène conjugué pourrait être due à un métabolisme de l'acide linoléique par des microorganismes [105]. Globalement, si les mammifères fabriquent des isoméres cis, les bactéries intestinales fabriquent des isomères trans. 
D’où, en conséquence, la répartition selon les aliments (tableau 17).

Tableau 17. Répartition des principaux isomères des acides linoléiques conjugués dans le beurre, le yaourt et la côte de bœuf.

\begin{tabular}{|l|l|}
\hline Aliment & Cis-9, trans-11 \\
\hline Beurre & $91 \%$ \\
\hline Yaourt & $82 \%$ \\
\hline Côte de bœuf & $60 \%$ \\
\hline
\end{tabular}

Les techniques de fabrication des fromages ont une influence sur leur contenu en CLA [106]. Pour ce qui concerne les fromages fermentés, la quantité d'acide linoléique (le précurseur des CLA) diminue

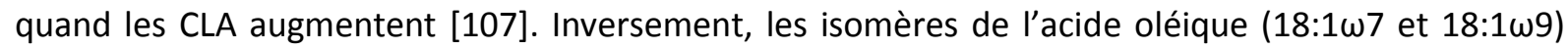
présentent une relation positive avec le contenu en CLA. Or, ces isomères constituent des intermédiaires lors de la biohydrogénation microbienne, de l'oxydation ou de l'isomérisation, des acides linoléique et alpha-linolénique. Le contenu en CLA augmente dans l'équivalent indien du yaourt (dahi), quand il est laissé après une nuit à température ambiante [108]. Les variations individuelles en biohydrogénation dans le rumen et en activité de delta-9-désaturase expliquent les variabilités de teneurs en CLA selon les animaux [109]. Par conséquent [107], les réactions métaboliques microbiennes sont responsables de la relation positive entre le contenu en CLA et celui des isomères de l'acide oléique. La synthèse endogène par action de la delta-9désaturase sur les 18:1-trans produisant du cis-9,11-trans est responsable de $64 \%$ des CLA présents dans le lait [110]; pour d'autres auteurs, le niveau se situe à $78 \%$ des CLA présents dans le lait de vache [111]. D'autant que la quantification des CLA duodénaux montre que la synthèse postabsortive constitue la source prédominante des CLA chez la vache laitière [112]. L'homme est capable de transformer l'acide vaccénique en CLA [113]. De ce fait, l'apport en acide vaccénique doit être soigneusement pris en compte dans toutes les mesures d'évaluation nutritionnelles. Les traitements industriels concernent soit le chauffage des corps gras dans les procédés de préparation des produits, dans la cuisson ménagère ou collective (dans ce cas, les huiles de friture peuvent être riches en divers (LA), soit la fabrication des margarines, en particulier lors de l'hydrogénation des huiles (mais, dans ce cas, la toxicologie des acides gras mono-insaturés trans doit aussi être évoquée, notamment dans le cadre cardiovasculaire). Lors des traitements industriels, il se forme des radicaux allyls, stabilisés par résonance ; puis la protonation contribue à la formation des CLA. In vitro, les produits d'oxydation des CLA ont des dérivés communs avec les furanes dans leur processus d'oxydation [114]. Mais il ne s'agit pas forcément des isomères biologiquement favorablement actifs.

\section{Présence dans les aliments}

D'une manière générale, le contenu en CLA est plus important dans les produits animaux que dans le monde végétal. Les CLA ont ainsi été trouvés dans les produits laitiers [89, 115, 116, 117] ; la plupart d'entre eux se situent généralement en moyenne entre 2,5 et $7 \mathrm{mg} / \mathrm{g}$ de graisses ; les desserts sans 
graisse, de même que les yaourts sans matière grasse ont des teneurs en CLA relativement faibles : entre 0,6 et $1,7 \mathrm{mg} / \mathrm{g}$ de matière grasse [115], mais les variations peuvent être importantes selon les produits et les auteurs. Dans le chocolat au lait, le seul CLA détecté a été le 9-cis,11-trans, représentant entre 0,1 et $0,2 \%$ des acides gras, ce qui correspond à une quantité de $0,3 \mathrm{mg} / \mathrm{g}$ de chocolat [118]. La constatation que les produits laitiers constituent une bonne source de CLA a engendré une série d'études afin d'y mesurer précisément les contenus [115]. Evidement, les CLA sont présents dans les viandes $[92,95,115,119$,] et même dans certains végétaux $[115,119]$. Ils sont détectés dans les aliments pour enfants [115].

\section{Comparaisons d'espèces}

Chez le bison, comme chez le bovin, l'élevage intensif induit la présence de moins de CLA, que l'élevage extensif, en prairie, à raison d'environ 30 \% (tableaux 18 et 19). En revanche, le $19: 1$ trans est considérablement réduit, de plus de 10 fois. Pour ce qui est du 22:6w3, sa teneur est moindre en intensif qu'en extensif. II y a moins de CLA dans l'élan et encore moins dans le poulet (l'aile). En revanche, le poulet contient beaucoup plus de 18:1 trans et de 22:6(w3) [120].

Tableau 18. Acides gras du semi-tendineux, en pourcentage des acides gras totaux. D'après Rule et al. [120].

\begin{tabular}{|c|c|c|c|c|c|c|}
\hline \multirow[t]{2}{*}{ Acides gras } & \multicolumn{2}{|l|}{ Bison } & \multicolumn{2}{|l|}{ Bovin } & \multirow[t]{2}{*}{ Élan } & \multirow[t]{2}{*}{ Poulet } \\
\hline & Extensif & Intensif & Extensif & Intensif & & \\
\hline $18: 1$ trans & 0,52 & 0,01 & 0,36 & 0,01 & 0,45 & 0,36 \\
\hline $\begin{array}{|ll|}\mathrm{c}-9, & \text { trans- } \\
11 & \end{array}$ & 0,39 & 0,37 & 0,32 & 0,28 & 0,10 & 0,07 \\
\hline $22: 6$, cis & 0,27 & 0,22 & 0,14 & 0,06 & 0,13 & 0,26 \\
\hline
\end{tabular}

Tableau 19. Acides gras du longissimus, en pourcentage des acides gras totaux. D'après Rule et al. [120]. La publication qualifie les élevages de range et de feedlot, équivalent d'élevages extensifs et intensifs.

\begin{tabular}{|l|l|l|l|l|l|l|}
\hline Acides gras & Bison & & Bovin & & Élan & Poulet \\
\cline { 2 - 6 } & Extensif & Intensif & Extensif & Intensif & & \\
\hline $18: 1$ trans & 0,16 & 0,01 & 0,14 & 0,01 & 0,29 & 0,36 \\
\hline c-9, trans-11 & 0,34 & 0,28 & 0,41 & 0,26 & 0,10 & 0,07 \\
\hline $22: 6$, cis & 0,23 & 0,18 & 0,09 & 0,04 & 0,11 & 0,26 \\
\hline
\end{tabular}




\section{CLA et lait}

Selon la saison, et donc la qualité du fourrage et la quantité absorbée, les teneurs peuvent varier de manière importante, de 0,4 à $1,4 \mathrm{~g} / 100 \mathrm{~g}$ de graisse de lait. Le lait d'une vache nourrie au pâturage contient plus de CLA que celui d'animaux recevant une ration mixte [121]. L'alimentation au pâturage augmente les CLA dans le lait, mais diminue la production en masse totale de lait (sans affecter le pourcentage de graisses ou de protéines dans le lait) (tableau 20) [122].

Tableau 20. Effet de l'alimentation au pâturage sur les teneurs en CLA, en acide linoléique et en acide alpha linolénique, en $\mathrm{mg} / \mathrm{g}$ d'acides gras.

\begin{tabular}{|l|l|l|l|l|}
\hline & $\mathbf{0}$ & $\mathbf{1 / 3}$ & $\mathbf{2 / 3}$ & $3 / 3$ \\
\hline Lait $(\mathrm{kg} / \mathrm{j})$ & & 24,5 & 17,5 & 14,5 \\
\hline CLA (mg/g acides gras) & 3,8 & 8,9 & 14,3 & 22,1 \\
\hline $18: 2 \mathrm{c}(\mathrm{mg} / \mathrm{g}$ acides gras) & 35,6 & 42,7 & 27,1 & 14,0 \\
\hline $18: 3 \mathrm{c}(\mathrm{mg} / \mathrm{g}$ acides gras) & 7,6 & 8,1 & 14,6 & 20,2 \\
\hline
\end{tabular}

Animaux Holstein formulation de l'alimentation. 1/3 signifie : un-tiers de pâturage (en foin d'alfalfa luzerne), le reste est de l'ensilage, $3 / 3$ signifie : pâturage total de mai à septembre. $18: 2 \mathrm{c}$ : acide linoléique de structure chimique cis. 18:3 c: acide alpha-linolénique de structure chimique cis. D’après Dhiman et al. [122].

Une étude a été menée pour déterminer le meilleur rapport entre le fourrage et le concentré pour produire des acides gras trans [123]. Le contenu en CLA du lait peut être modifié en adaptant les aliments de la vache [124]. Selon que les animaux reçoivent du fourrage ou des aliments concentrés, la teneur en CLA de leur lait varie de 2,5 à $17,7 \mathrm{mg} / \mathrm{g}$ de matière grasse. Mais les écarts obtenus sont plus importants que ceux observés sur divers laits commerciaux homogénéisés [115]. Nourrir des vaches avec une alimentation contenant des huiles de diverses natures modifie un peu la production de lait et y change le contenu en CLA ; la teneur maximale est obtenue avec l'huile de tournesol par rapport à l'huile d'arachide ou de lin $[125,126]$. Des teneurs croissantes en huile de soja accroissent les quantités de CLA dans le lait, plus que l'huile de lin, alors que la quantité totale de lait produite n'est pratiquement pas modifiée [127]. Une comparaison a été faite avec l'utilisation, chez la vache, d'huiles de " solin », canola et lin [128].

Ajouter des algues augmente les quantités des CLA, d'autant que celles-ci sont protégées (par le xylose, en l'occurrence) (tableau 21) [129]. 
Tableau 21. Effet de l'apport d'algues sur les teneurs en acides linoléiques conjugués du lait.

\begin{tabular}{|c|c|c|c|}
\hline & \multirow[t]{2}{*}{ Témoin } & \multicolumn{2}{|l|}{ Algues } \\
\hline & & protégées & non protégées \\
\hline Lait $(\mathrm{kg} / \mathrm{j})$ & 23,9 & 23,2 & 24,0 \\
\hline $\begin{array}{l}18: 1 \mathrm{t}-9 \quad(\mathrm{~g} / 100 \mathrm{~g} \\
\text { graisse })\end{array}$ & 0,9 & 1,0 & 1,1 \\
\hline $\begin{array}{ll}18: 3 \mathrm{c} & (\mathrm{g} / 100 \mathrm{~g} \\
\text { graisse }) & \end{array}$ & 0,5 & 0,5 & 0,5 \\
\hline $\begin{array}{ll}22: 6 \mathrm{c} & (\mathrm{g} / 100 \mathrm{~g} \\
\text { graisse }) & \end{array}$ & 0 & 0,8 & 0,5 \\
\hline CLA (g/100 g graisse) & 0,4 & 2,3 & 2,6 \\
\hline
\end{tabular}

Alimentation donnée pendant 6 semaines à raison de $910 \mathrm{~g} / \mathrm{j}$. Animaux Brown swiss et Holstein. 18:2, acide linoléique. 18:3, acide alpha-linolénique. 22:6, acide cervonique, acide docosahexaénoique, DHA. D'après Franklin et al. [129]. Nourrir des vaches (Holstein et Jersey) avec des aliments à base de poisson et de graines de soja extrudées augmente le contenu en CLA du lait (tableau 22) [130]. L'addition d'huile de poisson aux huiles végétales augmente les teneurs en CLA du lait [130]. L'effet de concentrations croissantes d'huiles de poisson (menhaden) dans l'alimentation induit un accroissement du 18:1-trans, des CLA totaux et du 22:6(w3), avec cependant une stabilisation, voire une légère diminution de ces composés avec la plus forte quantité d'huile de poisson (tableau 23) [131]. Nourrir des vaches avec des huiles de poisson modifie la fonction du rumen, stimulant une augmentation de la conversion de l'acide linoléique en acide vaccénique trans et en CLA [132].

Tableau 22. Facteur de multiplication dans le lait de vache. D’après Abu-Ghazaleh et al. [130].

\begin{tabular}{|l|l|l|l|}
\hline & $\mathbf{0 , 5}$ \% poisson & $\mathbf{2 , 5} \%$ graines soja & $\mathbf{0 , 5}$ \% poisson + 2,5 \% soja \\
\hline CLA cis-9, 11-trans & $X 0,4$ & $X 1,4$ & $X 3,2$ \\
\hline $\begin{array}{l}\text { Trans vaccénic } \\
\text { (TVA) }\end{array}$ & $\times 0,4$ & $X 1,8$ & $X 3,5$ \\
\hline
\end{tabular}

Tableau 23. Effet de la concentration croissante d'huile de menhaden, en $\mathrm{g} / 100 \mathrm{~g}$ d'acides gras totaux, en $\mathrm{g} / 100 \mathrm{~g}$ d'acides gras totaux. Alimentation donnée 35 jours, animaux Holstein. 18:3 c: 
acide alpha-linolénique de structure chimique cis. 22:6c: acide cervonique, DHA, acide docosahexaénoique de structure chimique cis. D'après Donovan et al. [131].

\begin{tabular}{|c|c|c|c|c|}
\hline & \multicolumn{4}{|c|}{ Huile (\% matière sèche de la ration) } \\
\hline & 0 & $1 \%$ & $2 \%$ & $3 \%$ \\
\hline $18: 1 \mathrm{t}-11$ & 1,2 & 3,1 & 6,1 & 4,5 \\
\hline CLA totaux & 0,7 & 1,7 & 2,5 & 2,1 \\
\hline$-c-9, t-11$ & 0,6 & 1,6 & 2,2 & 1,9 \\
\hline$-t-9, t-11$ & 0,1 & 0,1 & 0,3 & 0,2 \\
\hline $18: 3 c$ & 0,2 & 0,4 & 0,2 & 0,1 \\
\hline $22: 6 \mathrm{c}$ & 0,02 & 0,06 & 0,26 & 0,2 \\
\hline
\end{tabular}

L'utilisation de ces mêmes types d'alimentation n'induit pas de modification de goût pour le consommateur [133], quoique les teneurs de ces laits en graisse soit différente. L'addition d'huile de poisson (à raison de $2 \%$ de la ration des vaches de race Holstein) augmente le CLA dans le lait et dans le beurre [134].

\section{Alimentation animale et CLA dans les produits dérivés}

Nourrir des bœufs avec une alimentation à base de maïs supplémenté avec de l'huile de soja n'augmente pas les quantités des CLA dans la viande [135]. En revanche, donner une alimentation à haute teneur en oléate et en linoléate avec de l'huile de carthame (safflower) augmente les CLA dans les tissus de l'agneau [136]. Utiliser des graines de soja extrudées non dégraissées induit une faible augmentation du CLA dans les viandes (137]. Nourrir des poules avec une huile très riche en acide alpha-éléostéarique (cis-9, trans-11, trans-13) induit la présence des CLA dans tous les tissus et dans le jaune des œufs [138].

\section{Supplémentation directe avec les CLA}

Plutôt que de chercher à augmenter les teneurs en CLA dans les produits animaux en les nourrissant avec des précurseurs, il est possible d'ajouter directement les CLA dans les aliments destinés aux animaux. Chez les modèles animaux, l'efficacité nécessite environ $1 \%$ des CLA en poids dans les aliments.

Ajouter des CLA dans l'alimentation des poules peut augmenter la valeur nutritionnelle d'œufs déjà enrichis en oméga-3 [139]. Toutefois, apparaissent des modifications dans la composition en acides gras: diminution des acides oléique, arachidonique et cervonique, augmentation des acides linoléique, stéarique et palmitique ; ce qui laisse à penser que les CLA modifient les activités des delta-6 et delta-9-désaturases [140]. En fait, on ne retrouve pas exactement le même profil en divers 
CLA dans les lipides de l'œuf, en comparaison avec celui de ce qui est donné dans l'alimentation des poules pondeuses [140].

Tableau 24. Composition relative (pourcentage des acides linoléiques conjugués) dans l'alimentation, les lipides totaux du jaune d'œuf, ses phospholipides et ses triglycérides. D'après Yang et al. [140].

\begin{tabular}{|l|l|l|l|l|}
\hline CLA isomères & Aliment & Jaune total & Phospholipides & Triglycérides \\
\hline $\begin{array}{l}\text { cis-11, trans-13/trans- } \\
11, \text { cis-13 }\end{array}$ & 12,8 & 12,9 & 6,2 & 15,1 \\
\hline $\begin{array}{l}\text { cis-10, trans-12/trans- } \\
10, \text { cis-12 }\end{array}$ & 37,9 & 16,0 & 19,6 & 12,8 \\
\hline $\begin{array}{l}\text { cis-9, trans-11/trans-9, } \\
\text { cis-11 }\end{array}$ & 31,8 & 41,2 & 43,2 & 37,8 \\
\hline
\end{tabular}

Nourrir des poulets avec des CLA permet d'augmenter la valeur nutritionnelle de la viande qui sera consommée par l'homme [141]. Par contre, l'addition des CLA dans l'alimentation des poules diminue le contenu en acide oléique du jaune d'œuf, induit une mortalité embryonnaire et altère la qualité des œufs; cet effet adverse pourrait résulter d'une augmentation du taux en acides gras saturés, il peut être prévenu par l'addition d'huile d'olive [142]. Une perturbation a été notée dans la composition et la qualité des œufs: forme du jaune modifiée, etc. [143]. La présence des CLA dans la conserve de poulet cuit n'a que peu d'influence sur l'oxydation et la production de composés volatiles (lors de l'irradiation ou non) [144]. Après la cuisson, la viande des poulets nourris avec 2 ou $3 \%$ de CLA est plus dure et plus sèche, sa couleur un peu plus foncée ; ces modifications sont en relation avec la diminution des acides gras insaturés, ce qui augmente le point de fusion [145].

Chez la vache Holstein, I'addition de CLA sous sa forme 10-t,12-cis diminue la quantité de graisses dans le lait de $25 \%$ pour des quantités aussi faibles que $0,016 \%$ de matière sèche alimentaire. La diminution est globalement dose-dépendante, curvi-linéaire [146]. Le mécanisme impliqué serait la diminution de l'expression des gènes codant pour la captation et le transport des acides gras circulants, la synthèse de novo, la désaturation des acides gras et la synthèse des triglycérides (147]. Par ailleurs, une inhibition de la synthèse de novo et une réduction de l'utilisation des acides gras circulants ont été observées [148].

Toutefois, il n'a pas été mis en évidence de bactéries intestinales spécifiques de la vache qui produise le t-10, c-12 [149], ce qui est en fait logique compte tenu de la physiologie de l'animal, qui n'hébergerait pas de microorganismes susceptibles de diminuer sa propre lactation. Une autre étude a au contraire montré chez la vache que l'addition des CLA dans I'alimentation à raison de 50 ou $100 \mathrm{mg} / \mathrm{j}$ accroît les quantités dans le lait de 29 et 34 \% [150].

Les modifications de la qualité de la viande de lapin ont été abordées, en même temps que les variations de divers paramètres chez le lapin [151]. Chez le cochon, les CLA modifient les teneurs en acides gras [152], ils augmentent la teneur en acides gras saturés des muscles et modifient le goût [153]. En revanche, la stabilité de la couleur est améliorée [154]. Pour d'autres, les qualités 
organoleptiques ne sont pas modifiées $(\mathrm{pH}$, impédance, couleur, graisse intramusculaire, perte à la cuisson ou à la friture, qualités sensorielles) [155]. Nourrir des cochons avec de l'acide gras monoinsaturé trans augmente la quantité de cet acide dans la viande, mais aussi celle des CLA [156]. Les CLA sont incorporés dans les diverses classes de lipides des tissus du porc, en particulier dans le cœur, et plus spécifiquement (pour le cœur comme pour le foie) dans les phospholipides spécifiques de la membrane interne des mitochondries [157]. L'utilisation des CLA augmente le rapport prise de poids sur alimentation, augmente la surface du filet, diminue l'épaisseur de la graisse, améliore l'aspect marbré et la fermeté [158] et améliore la qualité du muscle [159].

Surcoût modeste pour le consommateur, augmentation considérable de la valeur nutritionnelle : exemples chiffrés

II est donc manifestement possible d'améliorer considérablement la valeur nutritionnelle, en particulier au niveau de la qualité des acides gras des graisses, mais aussi de certains micronutriments indispensables ou non, en reconsidérant la nourriture donnée aux animaux pour la rapprocher d'une alimentation traditionnelle, sinon naturelle [2]. Le surcoût reste modeste (tableau 25) par rapport au gain de valeur nutritionnelle : ainsi, l'augmentation de $5 \%$ du prix de l'œuf se traduit par une multiplication par 10 de son contenu en oméga-3, et par conséquent divise par presque autant le prix du gramme d’oméga-3. Pour le poisson, il devrait en être de même.

Tableau 25. Un exemple pratique : facteurs de multiplication de la valeur nutritionnelle par rapport au coût. D'après Weill et al. [18].

\begin{tabular}{|l|l|l|l|l|}
\hline Aliment & $\begin{array}{l}\text { Augmentation dans } \\
\text { aliment animal }\end{array}$ & $\begin{array}{l}\text { Surcoût aliment } \\
\text { animal }\end{array}$ & $\begin{array}{l}\text { Surcoût } \\
\text { production animal }\end{array}$ & $\begin{array}{l}\text { Augmentation } \\
\text { nutritionnelle, aliment homme }\end{array}$ \\
\hline Lait & X 7 (vache) & $5 \%$ & $2 \%$ & $X 3$ \\
\hline uf & X 9 (poule) & $5 \%$ & $1 \%$ & $X 11$ \\
\hline Porc & X 4 & $5 \%$ & $2 \%$ & $X 2,6$ \\
\hline Poulet & X 3 & $5 \%$ & $2 \%$ & $X 4,3$ \\
\hline Plein air, & & & $15 \%$ & \\
\hline Label & & & & \\
\hline
\end{tabular}

Actuellement, des produits riches en acides gras oméga-3 sont commercialisés. II est donc possible d'évaluer le coût de cette richesse [2]. Entre le label et le plein air d'une part et les œufs oméga3 Matines d'autre part, le surcoût de l'alimentation animale est de $5 \%$, soit $1 \%$ à la production, ce qui se traduit par une augmentation du prix de 3,6 \% pour le consommateur. La valeur nutritionnelle est multipliée par 9, le prix de l'unité oméga-3 est divisé par 10. 
Tableau 26. Coût des oméga-3 des œufs par rapport aux huiles végétales. Acide alpha-linolénique : 18:3w3. D'après Bourre [1, 2].

\begin{tabular}{|l|l|}
\hline Aliments & Euros pour $\mathbf{1} \mathbf{g}$ d'acide alpha-linolénique (50 \% des ANC) \\
\hline Colza & 0,015 \\
\hline Soja & 0,03 \\
\hline Noix & 0,05 \\
\hline Maïs & 0,25 \\
\hline Olive, œuf - lin standard & 0,9 \\
\hline Pépin de raisin, œuf oméga & 1,3 \\
3 M... & 2,6 \\
\hline Arachide & 0,12 \\
\hline Isio-4 & 8 \\
\hline uf standard & 12 \\
\hline uf label ou plein air & \\
\hline
\end{tabular}

\section{Conclusions}

Parmi les divers nutriments - outre les minéraux qui concernent plus particulièrement les œufs et les poissons-les lipides, ainsi que certaines vitamines et micronutriments liposolubles, sont particulièrement à prendre en compte dans la formulation de l'alimentation animale ; l'objectif étant de maintenir par le respect de la naturalité (sinon d'optimiser ou d'enrichir) la valeur nutritionnelle pour I'homme, qui en absorbe les produits dérivés. La présence d'acides gras oméga- $3 \mathrm{~s}$ 'avère absolument cruciale dans la formulation des aliments destinés aux animaux, dont les produits seront consommés par l'homme ; ceux-ci pourront en moduler sa physiologie et ses pathologies, ce qui leur confère un intérêt important en santé publique. Mais, compte tenu notamment des recommandations de l'Afssa et des ANC (apports nutritionnels conseillés pour la population française), il convient de sélectionner en priorité, parmi les aliments destinés à la consommation humaine, ceux qui apportent plusieurs décigrammes quotidiens d'acide alpha-linolénique. En effet, l'absorption moyenne est inférieure à $1 \mathrm{~g}$ quotidien, alors que les ANC journaliers sont, respectivement, de 2 et de 1,6 g pour les hommes et les femmes adultes. Schématiquement, en alimentation humaine usuelle en France, ce sont les huiles de colza (au premier chef), de noix (mais elle est plus onéreuse que celle de colza) et de soja (mais elle contient de l'acide linoléique, oméga-6, en grande quantité) et une variété d'œufs bien définie, les œufs oméga-3 (et non, généralement, les œufs label ou bio) et aussi les noix. Les apports par le pourpier (en Grèse) ou la mâche (en France) restent modestes, compte tenu de leurs consommations habituelles. En Amérique du nord, le " nouveau colza » se dénomme canola. Au Japon, I'huile de périlla est très utilisée. L’huile de chanvre 
(dépourvue de cannabinoïdes) reste confidentielle. À ce jour, l'huile de lin est interdite pour la consommation humaine en France. En ce qui concerne les très longues chaînes carbonées oméga-3, il s'agit des poissons gras sauvages et d'élevage (à la condition expresse que leur nourriture ait été satisfaisante, préoccupation qui fait l'objet d'un chapitre de cette revue) ainsi que les œufs oméga-3 ; les ANC quotidiens pour le DHA, 22:6 33 , sont respectivement de 120 et de $100 \mathrm{mg}$ pour les hommes et les femmes adultes. Mais accroître la quantité d'acides gras oméga-3 dans les aliments n'est pas suffisant, bien que fondamental. II faut tenir compte de la présence d'acides gras oméga- 6 , afin que la rapport oméga-6/oméga-3 se rapproche des recommandations, c'est-à-dire de 5 . Or, ce rapport est beaucoup trop élevé dans I'alimentation de la population française. II ne sera efficacement abaissé que par l'augmentation quantitative des acides gras oméga-3; mais certainement pas avec une diminution des oméga-6, dont les apports ne sont que légèrement supérieurs aux recommandations. Dans cet esprit, il est inepte que la viande bovine soit mise en valeur dans certaines publicités médicales comme étant riche en acide arachidonique (oméga-6). Les aliments dont le rapport est inférieur à 5 seront qualifiés d'équilibrants (car corrigeant un rapport trop grand dans I'alimentation usuelle des Français), ceux dont le rapport sera proche de 5 seront qualifiés d'équilibrés.

Si, dans le cadre de la couverture des besoins en oméga-3 chez l'homme, le lait issu de vaches nourries avec des graines de lin n'a pratiquement pas d'intérêt; en revanche, le lait enrichi (après sa traite) avec des oméga-3 (par des micro-gélules, par exemple, devenant alors une boisson lactée) est certainement efficace, comme tout autre aliment vecteur, tel le pain. Mais il s'agit alors d'aliments fonctionnels obtenus par suplémentation (ex. alicaments), dont l'étude sort du cadre de cette revue. L'intérêt de certains aliments composés avec des graines de colza ou de lin (tel le pain) repose sur la quantité réelle qu'ils apportent en acides gras oméga-3.

Dans les aliments destinés à l'homme, il convient par ailleurs que les teneurs en acides gras saturés ne soient pas trop importantes. C'est ainsi que le beurre oméga-3, obtenu à partir du lait de vaches nourries avec des graines de lin, est sans intérêt nutritionnel par rapport à la couverture en oméga-3 de l'homme (car contenant beaucoup trop peu d'acides gras oméga-3 et trop d'acides gras saturés) ; certaines margarines sont appréciables dans la mesure où elles sont partiellement formulées avec de I'huile de colza (mais certaines présentent un rapport oméga-6/oméga-3 trop élevé). Globalement et schématiquement, compte tenu des connaissances actuelles, les viandes d'animaux polygastriques ne sont pas significativement utiles (viande ovine, mouton, etc.), celles des animaux mono-gastriques sont intéressantes (lapin, cochon, avec une mention particulière pour le jambon cuit), celles des volailles le sont un peu plus. Pour ce qui est des œufs et des poissons, l'impact est extrêmement important.

En effet, de manière générale, les teneurs en acides gras poly-insaturés des lipides de chair de poisson de consommation courante varient entre 7 et $37 \%$, alors que, pour les animaux terrestres, elles se situent entre 0,5 et $2 \%$ [160] ; cette observation implique donc un effet plus grand de I'alimentation des poissons sur la valeur nutritionnelle de leur chair. La valeur nutritionnelle des poissons varie de façon importante selon l'âge, le cycle sexuel, la saison, l'habitat; mais les différences sont encore plus notables en fonction des méthodes d'élevage, comme le montre cette revue. Or, le consommateur français mange de plus en plus de poisson d'élevage [161], la perception de leur qualité dépend d'ailleurs en fait de multiples facteurs [162, 163] ainsi que la valeur nutritionnelle [160]. La part de produits transformés occupe une place importante dans la consommation de poisson pour ce qui concerne la population française; or, curieusement, la 
documentation manque sur l'effet des diverses techniques de conservation sur la préservation des acides gras oméga-3, y compris pour la conserve appertisée et la congélation. Or, ces techniques de conservation assurent un peu moins des deux tiers de la consommation de poisson en France [161]. De plus, une conserve dans I'huile (qui capte une partie des acides gras oméga-3) en diminue la consommation par l'homme, car l'huile n'est généralement pas absorbée. L'effet du fumage ne se résume pas à une augmentation de la teneur en sodium, mais pourrait modifier (probablement légèrement) sa valeur nutritionnelle. Par ailleurs, pour ce qui concerne diverses méthodes de cuisson, c'est-à-dire les préparations culinaires, les conséquences, les effets éventuellement destructeurs sur les acides gras oméga-3 sont relativement mal connus. Après la publication des ANC [164], l'Afssa [165] recommande de vérifier la présence des oméga-3 dans les produits transformés et de vérifier l'absence de produits d'oxydation.

Incidemment, ces préoccupations de nutrition animale doivent concerner tous les élevages, par exemple ceux d'escargots. Car ces animaux fournissent aux Crétois une fraction de leurs acides gras oméga-3 ; directement, car ces gastéropodes en sont riches et indirectement car ils sont mangés par les poules, qui concentrent les oméga-3 dans leurs œufs. Les grenouilles sont issues d'élevages pour une grande part; or, l'impact de l'alimentation des batraciens est mal connu, tout au moins au niveau de leur valeur nutritionnelle en consommation humaine. Pour ce qui concerne les CLA, nombreuses sont les données scientifiques, qu'elles soient expérimentales, vétérinaires ou médicales, mais elles ne permettent pas encore de conclure favorablement pour ce qui concerne la santé de l'homme, du moins à travers la présence de ces substances dans des aliments issus d'animaux nourris eux-mêmes avec des CLA. L'intérêt de la supplémentation directe de la nourriture humaine avec tel ou tel isomère est un autre problème, qui ne relève pas du cadre de cette revue. La lutéine et la zéaxanthine des œufs méritent d'être fortement valorisées.

Par ailleurs, il convient que le consommateur sache choisir les morceaux de découpe ou les filets et les préparer avant de les manger [2]. Car chaque espèce recèle des morceaux maigres et d'autres gras. Par exemple, deux recettes de pot-au-feu peuvent induire des teneurs en graisses très différentes, selon qu'il est confectionné avec du plat de côte ( $16 \%$ de lipides) ou du jarret (4\% de lipides). La cuisson a une influence sur la teneur en graisses, mais moins qu'il n'est généralement affirmé. La grillade n'élimine pas toutes les graisses; de même que l'utilisation de matière grasse dans une préparation n'est pas toujours un facteur déterminant de la teneur en lipides. En effet, une grillade peut parfois être plus grasse qu'un plat en sauce. Par exemple, une part d'entrecôte grillée contient encore $12 \%$ de lipides, alors qu'une portion normale de bœuf bourguignon n'en recèle que $7 \%$.

Par ailleurs, il reste malheureusement à répéter que tous les poissons ne sont pas maigres, tous ne sont pas gras non plus; toutes les viandes ne sont pas plus grasses que n'importe quel poisson. Le jambon cuit et le bifteck se situent parmi les poissons maigres; le rosbif, l'escalope de dinde et le faux filet se retrouvent parmi les poissons mis-gras. Finalement, l'entrecôte et les côtelettes de mouton ou de porc sont moins grasses que certains poissons, comme le maquereau ou l'anguille. Il convient de savoir non seulement choisir mais aussi cuire. L'influence des préparations est évidemment primordiale. Par exemple, pour la teneur en graisses du carrelet, qui n'est que de $2 \%$ quand il est cuit à la vapeur, atteint $16 \%$ dès qu'il est frit. Des écarts similaires se retrouvent avec la limande nature ou panée. Quant au hareng, il contient autant de graisses, qu'il soit cru ou frit. Mais ce ne sont pas les mêmes. En effet, pour de strictes raisons physicochimiques de dissolutions 
mutuelles des corps gras, les graisses de ce poisson gras se dissolvent dans celles du bain de friture non consommé ; en revanche ce poisson s'imprègne des huiles du bain de friture qui se substituent à celles qui étaient naturellement présentes. La valeur nutritionnelle du poisson pané ou frit dépend donc presque intégralement de la valeur nutritionnelle de l'huile utilisée pour sa cuisson. Elle doit être insaturée, au minimum mono-insaturée, les mélanges de type Isio-4 étant optimisés dans ce domaine. Ainsi donc, en fonction de son élevage et selon sa préparation culinaire, le poisson prévient ou accélère les maladies cardiovasculaires, entre autres.ll est grand temps que les cahiers des charges imposés aux producteurs et aux éleveurs par la distribution et de la restauration collective au premier chef ne se contentent plus de requérir l'absence de toxiques, mais aussi définissent la réelle valeur nutritionnelle des aliments. Cela est urgent pour les poissons et les œufs, entre autres.

Ce travail a été soutenu par la FCD (Fédération des entreprises du commerce et de la distribution), Monsieur Jérôme Bédier.

\section{RÉFÉRENCES}

1. Bourre JM (2003a). Relations entre acides gras oméga-3, oméga-9, structures et fonctions du cerveau. Le point sur les dernières données. Le coût financier alimentaire des oméga-3. OCL, $10: 1$ 10.

2. Bourre JM (2003b). Diététique du cerveau : la nouvelle donne. Editions Odile Jacob.

3. Bourre JM, Dumont O, Piciotti M (1996). Les acides gras de la famille alpha-linolénique contrôlent la structure et la fonction du cerveau : leur nature, leur rôle, origine et importance alimentaire. $O C L$, $2: 254-63$.

4. Chalon S (2001). Acides gras poly-insaturés et fonctions cognitives. OCL, 4 : 317-20.

5. Mendy $F$ (2002). $93^{e}$ congrès de l'AOCS (Montréal, 5-8 mai 2002) : l'essentiel du programme nutrition. $O C L, 9$ : 283-9.

6. Combe N, Boué $C$ (2001). Apports alimentaires en acides linoléique et alpha-linolénique d'une population d'Aquitaine. OCL, $8: 118-121$.

7. Bourre JM, Dumont O, Durand G (2000). Effet-dose de l'acide oléique alimentaire. Cet acide est-il conditionnellement essentiel ? OCL, 7 : 524-30.

8. Bourre JM, Dumont O (2003c). Dietary oleicacid not used during brain development and in adult in rat, in contrast with sciatic nerve. Neurosci Lett, $336: 180-4$.

9. Sebedio JL, Brétillon L, Chardigny JM (2001). Conjugated linoleic acid (CLA) and functional food ? $O C L, 8: 328-32$.

10. Martin A (2001). Les « alicaments »: du marketing à la santé publique. $O C L, 8: 310-1$.

11. Bourre JM, Faivre A, Dumont $O$, et al. (1983). Effect of polyunsaturated fatty acids on fetal mouse brain cells in culture in a chemically defined medium. J Neurochem, 41 : 1234-42. 
12. Bourre JM, Pascal G, Durand G, Masson M, Dumont O, Piciotti M (1984). Alterations in the fatty acid composition of rat brain cells (neurons, astrocytes and oligodendrocytes) and of subcellular fractions (myelin and synaptosomes) induced by a diet devoided of (n-3) fatty acids. J Neurochem, $43: 342-8$.

13. Bourre JM, François M, Youyou A, et al. (1989). The effects of dietary alpha-linolenic acid on the composition of nerve membranes, enzymatic activity, amplitude of electrophysiological parameters, resistance to poisons and performance of learning task in rat. J Nutr, $119: 1880-92$.

14. Innis SM, Elias SL (2003). Intakes of essential n-6 and n-3 polyunsaturated fatty acids among pregnant Canadian women. Am J Clin Nutr, 77 : 473-8.

15. Xiang $M$, Alfven $G$, Blennow $M$, Trygg $M$, Zetterstrom R (2000). Long-chain polyunsaturated fatty acids in human milk and brain growth during early infancy. Acta Paediatr, 89 : 142-7.

16. Abaza L, Msallem M, Daoud D, Zarrouk M (2002). Caractérisation des huiles de sept variétés d'oliviers tunisiens. OCL, 9 :174-9.

17. Ashes J, Siebert B, Gulati S, Cuthbertson A, Scott T (1992). Incorporation of n-3 fatty acids of fish oil into tissue and serum lipid of ruminants. Lipids, $27: 629-31$.

18. Weill P, Schmitt B, Chesneau G, Daniel N, Safraou F, Legrand P (2002). Effects of introducing linseed in livestock diet on blood fatty acid composition of consumers of animal products. Ann Nutr Metab, 46 : 182-91.

19. Kitessa S, Gulati S, Ashes J, Scott T, Nichols P (2001). Utilisation of fish oil in ruminants. II. Transfer of fish oil fatty acids into goat's milk. Anim Feed Sci Technol, 89 : 201-8.

20. Specht-Overholt S, Romans JR, Marchello MJ, et al. (1997). Fatty acid composition of commercially manufactured omega-3 enriched pork products, haddock, and mackerel. J Anim Sci, $75: 2335-43$.

21. Scollan ND, Choi NJ, Kurt E, Fisher AV, Enser M, Wood JD (2001). Manipulating the fatty acid composition of muscle and adipose tissue in beef cattle. Br J Nutr, $85: 115-24$.

22. Ponnampalam EN, Sinclairt AJ, Egan AR, Blakeley SJ, Leury BJ (2001). Effect of diets containing n3 fatty acids on muscle long-chain n-3 fatty acid content in lambs fed low- and medium-quality roughage diets. J Anim Sci, 79 : 698-706.

23. Ponnampalam EN, Sinclair AJ, Hosking BJ, Egan AR (2002). Effects of dietary lipid type on muscle fatty acid composition, carcass leanness, and meat toughness in lambs. J Anim Sci, 80 : 628-36.

24. Keady TW, Mayne CS, Fitzpatrick DA (2000). Effects of supplementation of dairy cattle with fish oil on silage intake, milk yield and milk composition. J Dairy Res, 67 : 137-53.

25. Hoffmann E (1991). Fish in aquaculture and omega-3 fatty acids. Omega 3 News, 4 : 1-3.

26. Bell MV, Dick JR, Porter AE (2001). Biosynthesis and tissue deposition of docosahexaenic acid (22:6n-3) in rainbow trout (Oncorhynchus mykiss). Lipids, 36 : 1153-9. 
27. Dosanjh B, Higgs D, Plotnikoff D, McBride J, Markert J, Buckley J (1984). Efficacy of canola oil, pork lard and marine oil singly or in combination as supplemental dietary lipid sources for juvenil coho salmon (oncorhynchus kisutch). Aquaculture, 36 : 333-45.

28. Skonberg D, Rasco B, Dong F (1994). Fatty acid composition of salmonid muscles changes in response to high oleic acid diet. J Nutr, 124 : 1628-38.

29. Ackman RG (1989). Nutritional composition of fats in seafoods. Prog Food Nutr Sci, 13 : 161-289.

30. Yu TC, Sinnhuber RO, Putnam GB (1977). Effect of dietary lipids on fatty acid composition of body lipid in rainbow trout (Salmo gairdneri). Lipids, 12 : 495-9.

31. Van Vliet $T$, Katan $M(1990)$. Lower ration of $n-3$ to $n-6$ fatty acids in cultured than in wild fish. Am J Clin Nutr, $51: 1-2$.

32. Chanmugam $P$, Boudreau $M$, Boutte $T$, et al. (1992). Incorporation of different types of $n-3$ fatty acids into tissue lipids of poultry. Poult Sci, 71 : 516-21.

33. Van Elswyk ME, Hatch SD, Stella GG, Mayo PK, Kubena KS (1998). Poultry-based alternatives for enhancing the omega 3 fatty acid content of American diets. World Rev Nutr Diet, 83 :102-15.

34. Ayerza R, Coates W, Lauria M (2002). Chia seed (Salvia hispanica L.) as an omega-3 fatty acid source for broilers : influence on fatty acid composition, cholesterol and fat content of white and dark meats, growth performance, and sensory characteristics. Poult Sci, 81 : 826-37.

35. Simopoulos AP, Salem N (1989). $n-3$ fatty acids in eggs from range-fed greek chickens. Teh N Engl J Med, $16: 1412$.

36. Simopoulos AP, Salem N (1992). Egg yolk as a source of long-chain polyunsaturated fatty acids in infant feeding. Am J Clin Nutr, 55 : 411-4.

37. Cherian G, Sim JS (1991). Effect of feeding full fat flax and canola seeds to laying hens on the fatty acid composition of eggs, embryos, and newly hatched chicks. Poultry Sci, 70 : 917-22.

38. Anderson GJ, Connor WE, Corliss JD, Lin DS (1989). Rapid modulation of the $n-3$ docosahexaenoic acid levels in the brain and retina of the newly hatched chick. J Lipid Res, $30: 433-41$.

39. Jiang Z, Sim JS (1992). Effects of dietary $n-3$ fatty acid-enriched chicken eggs on plasma and tissue cholesterol and fatty acid composition of rats. Lipids, $27: 279-84$.

40. Ide T, Murata M (1994). Depressions by dietary phospholipids of soybean and egg yolk origins of hepatic triacylglycerol and fatty acid synthesis in fasted-refed rats. Ann Nutr Metab, 38 : 340-8.

41. Carrie I, Guesnet $P$, Bourre JM, Frances $H$ (2000a). Diets containing long-chain $n$ 3 polyunsaturated fatty acids affect behaviour differently during development than ageing in mice. $\mathrm{Br}$ J Nutr, $83: 439-47$.

42. Carrie I, Clement M, de Javel D, Frances H, Bourre JM (2000b). Phospholipid supplementation reverses behavioral and biochemical alterations induced by $n-3$ polyunsaturated fatty acid deficiency in mice. J Lipid Res, $41: 473-80$. 
43. Carrie I, Clement M, de Javel D, Frances H, Bourre JM (2000c). Specific phospholipid fatty acid composition of brain regions in mice. Effects of $n-3$ polyunsaturated fatty acid deficiency and phospholipid supplementation. J Lipid Res, 41 : 465-72.

44. Carrie I, Smirnova M, Clement M, de Javel D, Frances H, Bourre JM (2002). Docosahexaenoic acidrich phospholipid supplementation : effect on behavior, learning ability, and retinal function in control and n-3 polyunsaturated fatty acid deficient old mice. Nutr Neurosci, 5 : 43-52.

45. Oh SY, Ryue J, Hsieh CH, Bell DE (1991). Eggs enriched in omega-3 fatty acids and alterations in lipid concentrations in plasma and lipoproteins and in blood pressure. Am J Clin Nutr, 54 : 689-95.

46. O'Brien BC, Andrews VG (1993). Influence of dietary egg and soybean phospholipids and triacylglycerols on human serum lipoproteins. Lipids, 28 : 7-12.

47. Ferrier LK, Caston LJ, Leeson S, Squires J, Weaver BJ, Holub BJ (1995). alpha-Linolenic acid- and docosahexaenoic acid-enriched eggs from hens fed flaxseed : influence on blood lipids and platelet phospholipid fatty acids in humans. Am J Clin Nutr, 62 : 81-6.

48. Lewis NM, Schalch K, Scheideler SE (2000). Serum lipid response to $n-3$ fatty acid enriched eggs in persons with hypercholesterolemia. J Am Diet Assoc, 100 : 365-7.

49. Farrell DJ (1998). Enrichment of hen eggs with $n-3$ long-chain fatty acids and evaluation of enriched eggs in humans. Am J Clin Nutr, $68: 538-44$.

50. Agostoni C, Marangoni F, Giovannini M, Galli C, Riva E (2001). Prolonged breast-feeding (six months or more) and milk fat content at six months are associated with higher developmental scores at one year of age within a breast-fed population. Adv Exp Med Biol, 501 : 137-41.

51. Chirouze V, Lapillonne A, Putet G, Salle BL (1994). Red blood cell fatty acid composition in lowbirth-weight infants fed either human milk or formula during the first months of life. Acta Paediatr Suppl, $405:$ : 70-7.

52. Decsi T, Thiel I, Koletzko B (1995). Essential fatty acids in full term infants fed breast milk or formula. Arch Dis Child Fetal Neonatal, Ed. 72 : F23-F28.

53. Kohn G, Sawatzki G, van Biervliet JP (1994). Long-chain polyunsaturated fatty acids in infant nutrition. Eur J Clin Nutr, 48 : S1-S7.

54. Bondia-Martinez E, Lopez-Sabater MC, Castellote-Bargallo Al, et al. (1998). Fatty acid composition of plasma and erythrocytes in term infants fed human milk and formulae with and without docosahexaenoic and arachidonic acids from egg yolk lecithin. Early Hum Dev, 53 : S109-S119.

55. Cherian G, Sim JS (1996). Changes in the breast milk fatty acids and plasma lipids of nursing mothers following consumption of n-3 polyunsaturated fatty acid enriched eggs. Nutrition, $12: 8-12$.

56. Crissey SD, Slifka KA, Lintzenich BA (1999). Whole body cholesterol, fat, and fatty acid concentrations of mice (Mus domesticus) used as a food source. J Zoo Wildl Med, 30 : 222-7.

57. Gandemer G (1997). Lipides du muscle et qualité de la viande. Phospholipides et flaveur. OCL, 4 : 19-25. 
58. Elmore JS, Mottram DS, Enser M, Wood JD (1999). Effect of the polyunsaturated fatty acid composition of beef muscle on the profile of aroma volatiles. J Agric Food Chem, 47 : 1619-25.

59. Elmore JS, Mottram DS (2000). Formation of 2-alkyl-(2H)-thiapyrans and 2-alkylthiophenes in cooked beef and lamb. J Agric Food Chem, $48: 2420-4$.

60. Gonzalez-Esquerra R, Leeson S (2000). Effects of menhaden oil and flaxseed in broiler diets on sensory quality and lipid composition of poultry meat. Br Poultry Sci, 41 : 481-8.

61. Leskanich CO, Matthews KR, Warkup CC, Noble RC, Hazzledine M (1997). The effect of dietary oil containing ( $n-3)$ fatty acids on the fatty acid, physicochemical, and organoleptic characteristics of pig meat and fat. J Anim Sci, $75: 673-83$.

62. Romans JR, Wulf DM, Johnson RC, Libal GW, Costello WJ (1995a). Effects of ground flaxseed in swine diets on pig performance and on physical and sensory characteristics and omega-3 fatty acid content of pork : II. Duration of $15 \%$ dietary flaxseed. J Anim Sci, 73 : 1987-99.

63. Romans JR, Johnson RC, Wulf DM, Libal GW, Costello WJ (1995b). Effects of ground flaxseed in swine diets on pig performance and on physical and sensory characteristics and omega-3 fatty acid content of pork : I. Dietary level of flaxseed. J Anim Sci, 73 : 1982-6.

64. Marshall A, Sams A, Van Elswyk M (1994). Oxidative stability and sensory quality of stored eggs from hens fed $1.5 \%$ menhaden oil. J Food Sci, 59 : 561-3.

65. Li S, Sauer WC (1994). The effect of dietary fat content on amino acid digestibility in young pigs. J Anim Sci, 72 : 1737-43.

66. Olomu JM, Baracos V (1991). Prostaglandin synthesis and fatty acid composition of phospholipids and triglycerides in skeletal muscle of chicks fed combinations of flaxseed oil and animal tallow.

Lipids, $26:$ 743-9.

67. Haard N (1992). Control of chemical composition and food quality attributes of cultured fish. Food Research Internat, 25 : 289-307.

68. Clement M, Dinh L, Bourre JM (1995). Uptake of dietary RRR-alpha- and RRR-gamma-tocopherol by nervous tissues, liver and muscle in vitamin-E-deficient rats. Biochim Biophys Acta, 1256 : 175-80.

69. Clement M, Bourre JM (1997). Graded dietary levels of RRR-gamma-tocopherol induce a marked increase in the concentrations of alpha- and gamma-tocopherol in nervous tissues, heart, liver and muscle of vitamin-E-deficient rats. Biochim Biophys Acta, 1334 : 173-81.

70. Meluzzi A, Sirri F, Manfreda G, Tallarico N, Franchini A (2000). Effects of dietary vitamin E on the quality of table eggs enriched with n-3 long-chain fatty acids. Poult Sci, 79 : 539-45.

71. Rey Al, Lopez-Bote CJ (2001). Effect of dietary copper and vitamin E supplementation, and extensive feeding with acorn and grass on longissimus muscle composition and susceptibility to oxidation in Iberian pigs. J Anim Physiol Anim Nutr (Berl) 85 : 281-92. 
72. Boggio SM, Hardy RW, Babbit JK, Brannon EL (1985). The influence of dietary lipid source and alpha-tocopheryl acetate level on product quality of rainbow trout (salmo gairdneri). Aquaculture, $51: 13-24$.

73. Ohrvall M, Gustafsson I B, Vessby B (2001). The alpha and gamma tocopherol levels in serum are influenced by the dietary fat quality. J Hum Nutr Diet, $14: 63-8$.

74. McGraw KJ, Hill GE, Stradi R, Parker RS (2002). The effect of dietary carotenoid access on sexual dichromatism and plumage pigment composition in the American goldfinch. Comp Biochem Physiol $B$ Biochem Mol Biol, 131 : 261-9.

75. Johnson EJ (2002a). The role of carotenoids in human health. Nutr Clin Care, 5 : 56-65.

76. Schaeffer JL, Tyczkowski JK, Parkhurst CR, Hamilton PB (1988). Carotenoid composition of serum and egg yolks of hens fed diets varying in carotenoid composition. Poult Sci, 67 : 608-14.

77. Ben Amotz A, Edelstein S, Avron M (1986). Use of the beta-carotene rich alga Dunaliella bardawil as a source of retinol. Br Poult Sci, 27 : 613-9.

78. Johnson EJ, Hammond BR, Yeum KJ, et al. (2002). Relation among serum and tissue concentrations of lutein and zeaxanthin and macular pigment density. Am J Clin Nutr, 71 : 1555-62.

79. Farombi EO, Britton $G$ (1999). Antioxidant activity of palm oil carotenes in peroxyl radicalmediated peroxidation of phosphatidyl choline liposomes. Redox Rep, 4 : 61-8.

80. Khachik F, Bernstein PS, Garland DL (1997). Identification of lutein and zeaxanthin oxidation products in human and monkey retinas. Invest Ophthalmol Vis Sci, $38: 1802-11$.

81. Handelman GJ, Nightingale ZD, Lichtenstein AH, Schaefer EJ, Blumberg JB (1999). Lutein and zeaxanthin concentrations in plasma after dietary supplementation with egg yolk. Am J Clin Nutr, 70 : 247-51.

82. Sommerburg O, Keunen JE, Bird AC, van Kuijk FJ (1998). Fruits and vegetables that are sources for lutein and zeaxanthin : the macular pigment in human eyes. Br J Ophthalmol, 82 : 907-10.

83. Landrum JT, Bone RA, Joa H, Kilburn MD, Moore LL, Sprague KE (1997). A one year study of the macular pigment : the effect of 140 days of a lutein supplement. Exp Eye Res, 65 : 57-62.

84. Seddon JM, Ajani UA, Sperduto RD, et al. (1994). Dietary carotenoids, vitamins A, C, and E, and advanced age-related macular degeneration. Eye Disease Case-Control Study Group. JAMA 272 : 1413-20.

85. Surai PF, MacPherson A, Speake BK, Sparks NH (2000). Designer egg evaluation in a controlled trial. Eur J Clin Nutr, $54:$ 298-305.

86. Moeller SM, Jacques PF, Blumberg JB (2000). The potential role of dietary xanthophylls in cataract and age-related macular degeneration. J Am Coll Nutr, 19 : 522S-527S.

87. Kasahara T, Kato T (2003). A new redox-cofactor vitamin for mamals. Nature, $422: 832$. 
88. He K, Nukada H, Urakami T, Murphy MP (2003). Antioxidant and pro-oxidant properties of pyrroloquinoline quinone $(\mathrm{PQQ})$ : implications for its function in biological systems. Biochem Pharmacol, 65 : 67-74.

89. Werner S, Luedecke L, Shultz T (1992). Determination of conjugated linoleic acid content and isomer distribution in three Cheddar-type cheeses : effects of cheese cultures, processing, and aging. J Agric Food Chem, 40 : 1817.

90. Pariza MW, Loretz LJ, Storkson JM, Holland NC (1983). Mutagens and modulator of mutagenesis in fried ground beef. Cancer Res, $43: 2444 S-2446 S$.

91. Shantha N, Crum AD, Decker EA (1994). Evaluation of conjugated linoleic acid concentrations in cooked beef. J Agric Food Chem, 42 : 1757-60.

92. Ha YL, Grimm NK, Pariza MW (1987). Anticarcinogens from fried ground beef : heat-altered derivatives of linoleic acid. Carcinogenesis, 8 : 1881-7.

93. Ha YL, Storkson J, Pariza MW (1990). Inhibition of benzo(a)pyrene-induced mouse forestomach neoplasia by conjugated dienoic derivatives of linoleic acid. Cancer Res, 50 : 1097-101.

94. Ip C, Chin SF, Scimeca JA, Pariza MW (1991). Mammary cancer prevention by conjugated dienoic derivative of linoleic acid. Cancer Res, 51 : 6118-24.

95. Pariza MW, Hargraves WA (1985). A beef-derived mutagenesis modulator inhibits initiation of mouse epidermal tumors by 7,12-dimethylbenz[a]anthracene. Carcinogenesis, $6: 591-3$.

96. Shultz TD, Chew BP, Seaman WR, Luedecke LO (1992a). Inhibitory effect of conjugated dienoic derivatives of linoleic acid and beta-carotene on the in vitro growth of human cancer cells. Cancer Lett, $63: 125-33$.

97. Shultz, T.D., Chew, B.P., Seaman, W.R. (1992b) Differential stimulatory and inhibitory responses of human MCF-7 breast cancer cells to linoleic acid and conjugated linoleic acid in culture. Anticancer Res 12 : 2143-5.

98. Belury MA, Kempa-Steczko A (1997). Conjugated linoleic acid modulates hepatic lipid composition in mice. Lipids, 32 : 199-204.

99. Kepler CR, Tove SB (1967). Biohydrogenation of unsaturated fatty acids. 3. Purification and properties of a linoleate delta-12-cis, delta-11-trans-isomerase from Butyrivibrio fibrisolvens. J Biol Chem, 242 : 5686-92.

100. Kemp P, Lander DJ, Holman RT (1984). The hydrogenation of the series of methyleneinterrupted cis,cis-octadecadienoic acids by pure cultures of six rumen bacteria. Br J Nutr, 52 : 171-7. 101. Gurr MI (1987). Isomeric fatty acids. Biochem Soc Trans, 15 : 336-8.

102. Chin SF, Storkson JM, Liu W, Albright KJ, Pariza MW (1994). Conjugated linoleic acid (9,11- and 10,12 -octadecadienoic acid) is produced in conventional but not germ-free rats fed linoleic acid. $J$ Nutr, 124 : 694-701. 
103. Sebedio JL, Juaneda P, Dobson G, et al. (1997). Metabolites of conjugated isomers of linoleic acid (CLA) in the rat. Biochim Biophys Acta, $1345:$ 5-10.

104. Mosley EE, Powell GL, Riley MB, Jenkins TC (2002). Microbial biohydrogenation of oleic acid to trans isomers in vitro. J Lipid Res, $43: 290-6$.

105. Kakela $R$, Hyvarinen $H$, Vainiotalo $P(1996)$. Unusual fatty acids in the depot fat of the Canadian beaver (Castor canadensis). Comp Biochem Physiol B Biochem Mol Bio, 113 : 625-9.

106. Garcia- Lopez HS, Keough KJ, Arcos JA, Hill CGJ (2000). Interesterification (acidolysis) of butterfat with conjugated linoleic acid in a batch reactor. J Dairy Sci, 83 : 371-7.

107. Lin H, Boylston TD, Chang MJ, Luedecke LO, Shultz TD (1995). Survey of the conjugated linoleic acid contents of dairy products. J Dairy Sci, 78 : 2358-65.

108. Aneja R, Murthi T (1990). Conjugated linoleic acid contents of indian curds and gee. Ind Dairy Sci $43: 231-8$.

109. Peterson DG, Kelsey JA, Bauman DE (2002a). Analysis of variation in cis-9, trans-11 conjugated linoleic acid (CLA) in milk fat of dairy cows. J Dairy Sci, 85 : 2164-72.

110. Griinari JM, Corl BA, Lacy SH, Chouinard PY, Nurmela KV, Bauman DE (2000). Conjugated linoleic acid is synthesized endogenously in lactating dairy cows by Delta(9)-desaturase. J Nutr, 130 : 228591.

111. Corl BA, Baumgard LH, Dwyer DA, Griinari JM, Phillips BS, Bauman DE (2001). The role of Delta(9)-desaturase in the production of cis-9, trans-11 CLA. J Nutr Biochem, 12 : 622-30.

112. Piperova LS, Sampugna J, Teter BB, et al. (2002). Duodenal and milk trans octadecenoic acid and conjugated linoleic acid (CLA) isomers indicate that postabsorptive synthesis is the predominant source of cis-9-containing CLA in lactating dairy cows. J Nutr, $132: 1235-41$.

113. Turpeinen AM, Mutanen M, Aro A, et al. (2002). Bioconversion of vaccenic acid to conjugated linoleic acid in humans. Am J Clin Nutr, 76 : 504-10.

114. Yurawecz MP, Hood JK, Mossoba MM, Roach JA, Ku Y (1995). Furan fatty acids determined as oxidation products of conjugated octadecadienoic acid. Lipids, 30 : 595-8.

115. Chin SF, lui W, Strorkson JM, Ha YL, Pariza MW (1992). Dietary sources of conjugated dienoic isomers of linoleic acid, a newly recognized class of anticarcinogens. J Food Composition Analysis, 5 : 185-97.

116. Parodi PW (1997). Cows' milk fat components as potential anticarcinogenic agents. J Nutr, 127 : 1055-60.

117. Parodi PW (1999). Conjugated linoleic acid and other anticarcinogenic agents of bovine milk fat. J Dairy Sci, 82 : 1339-49.

118. Hurst WJ, Tarka SM, Dobson G, Reid CM (2001). Determination of conjugated linoleic acid (CLA) concentrations in milk chocolate. J Agric Food Chem 49 : 1264-5. 
119. Fogerty AC, Ford GL, Svoronos D (1988). Octadeca-9, 11-dienoic acid in foodstuffs and in the lipids of human blood and breast milk. Nutr Rep Int, 38 : 936-41.

120. Rule DC, Broughton KS, Shellito SM, Maiorano G (2002). Comparison of muscle fatty acid profiles and cholesterol concentrations of bison, beef cattle, elk, and chicken. J Anim Sci, 80 : 1202-11.

121. White SL, Bertrand JA, Wade MR, Washburn SP, Green JTJ, Jenkins TC (2001). Comparison of fatty acid content of milk from Jersey and Holstein cows consuming pasture or a total mixed ration. $J$ Dairy Sci, 84 : 2295-301.

122. Dhiman TR, Anand GR, Satter LD, Pariza MW (1999). Conjugated linoleic acid content of milk from cows fed different diets. J Dairy Sci, 82 : 2146-56.

123. Kucuk O, Hess BW, Ludden PA, Rule DC (2001). Effect of forage :concentrate ratio on ruminal digestion and duodenal flow of fatty acids in ewes. J Anim Sci, 79 : 2233-40.

124. Jiang J, Bjoerck L, Fonden R, Emanuelson M (1996). Occurrence of conjugated cis-9,trans-11octadecadienoic acid in bovine milk : effects of feed and dietary regimen. J Dairy Sci, 79 : 438-45.

125. Kelly ML, Berry JR, Dwyer DA, et al. (1998a). Dietary fatty acid sources affect conjugated linoleic acid concentrations in milk from lactating dairy cows. J Nutr, $128: 881-5$.

126. Kelly ML, Kolver ES, Bauman DE, Van Amburgh ME, Muller LD (1998b). Effect of intake of pasture on concentrations of conjugated linoleic acid in milk of lactating cows. J Dairy Sci, 81 : 16306.

127. Dhiman TR, Satter LD, Pariza MW, Galli MP, Albright K, Tolosa MX (2000). Conjugated linoleic acid (CLA) content of milk from cows offered diets rich in linoleic and linolenic acid. J Dairy Sci, 83 : 1016-27.

128. Ward AT, Wittenberg KM, Przybylski R (2002). Bovine milk fatty acid profiles produced by feeding diets containing solin, flax and canola. J Dairy Sci, 85 : 1191-6.

129. Franklin ST, Martin KR, Baer RJ, Schingoethe DJ, Hippen AR (1999). Dietary marine algae (Schizochytrium sp.) increases concentrations of conjugated linoleic, docosahexaenoic and transvaccenic acids in milk of dairy cows. J Nutr, 129 : 2048-54.

130. Abu-Ghazaleh AA, Schingoethe DJ, Hippen AR, Whitlock LA (2002). Feeding fish meal and extruded soybeans enhances the conjugated linoleic acid (CLA) content of milk. J Dairy Sci, 85 : 62431.

131. Donovan DC, Schingoethe DJ, Baer RJ, Ryali J, Hippen AR, Franklin ST (2000). Influence of dietary fish oil on conjugated linoleic acid and other fatty acids in milk fat from lactating dairy cows. J Dairy Sci, $83: 2620-8$.

132. Whitlock LA, Schingoethe DJ, Hippen AR, et al. (2002). Fish oil and extruded soybeans fed in combination increase conjugated linoleic acids in milk of dairy cows more than when fed separately. $J$ Dairy Sci, 85 : 234-43. 
133. Ramaswamy N, Baer RJ, Schingoethe DJ, et al. (2001). Composition and flavor of milk and butter from cows fed fish oil, extruded soybeans, or their combination. J Dairy Sci, 84 : 2144-51.

134. Baer RJ, Ryali J, Schingoethe DJ, Kasperson KM, et al. (2001).Composition and properties of milk and butter from cows fed fish oil. J Dairy Sci, 84 : 345-53.

135. Beaulieu AD, Drackley JK, Merchen NR (2002). Concentrations of conjugated linoleic acid (cis-9, trans-11-octadecadienoic acid) are not increased in tissue lipids of cattle fed a high-concentrate diet supplemented with soybean oil. J Anim Sci, 80 : 847-61.

136. Bolte MR, Hess BW, Means WJ, Moss GE, Rule DC (2002). Feeding lambs high-oleate or highlinoleate safflower seeds differentially influences carcass fatty acid composition. J Anim Sci, 80 : 60916.

137. Madron MS, Peterson DG, Dwyer DA, et al. (2002). Effect of extruded full-fat soybeans on conjugated linoleic acid content of intramuscular, intermuscular, and subcutaneous fat in beef steers. J Anim Sci, 80 : 1135-43.

138. Lee JS, Takai J, Takahasi K, et al. (2002). Effect of dietary tung oil on the growth and lipid metabolism of laying hens. J Nutr Sci Vitaminol, (Tokyo) 48 : 142-8.

139. Raes K, Huyghebaert G, De Smet S, Nollet L, Arnouts S, Demeyer D (2002). The deposition of conjugated linoleic acids in eggs of laying hens fed diets varying in fat level and fatty acid profile. $J$ Nutr, $132: 182-9$.

140. Yang L, Huang Y, James AE, Lam LW, Chen ZY (2002). Differential incorporation of conjugated linoleic acid isomers into egg yolk lipids. J Agric Food Chem, 50 : 4941-6.

141. Szymczyk B, Pisulewski PM, Szczurek W, Hanczakowski P (2001). Effects of conjugated linoleic acid on growth performance, feed conversion efficiency, and subsequent carcass quality in broiler chickens. Br J Nutr, $85:$ 465-73.

142. Aydin R, Pariza MW, Cook ME (2001). Olive oil prevents the adverse effects of dietary conjugated linoleic acid on chick hatchability and egg quality. J Nutr, 131 : 800-6.

143. Schafer K, Manner K, Sagredos A, Eder K, Simon O (2001). Incorporation of dietary linoleic and conjugated linoleic acids and related effects on eggs of laying hens. Lipids, $36: 1217-22$.

144. Du M, Ahn DU, Nam KC, Sell JL (2001). Volatile profiles and lipid oxidation of irradiated cooked chicken meat from laying hens fed diets containing conjugated linoleic acid. Poult Sci, 80 : 235-41.

145. Du M, Ahn DU (2002). Effect of dietary conjugated linoleic acid on the growth rate of live birds and on the abdominal fat content and quality of broiler meat. Poult Sci, 81 : 428-33.

146. Baumgard LH, Sangster JK, Bauman DE (2001). Milk fat synthesis in dairy cows is progressively reduced by increasing supplemental amounts of trans-10, cis-12 conjugated linoleic acid (CLA). J Nutr, 131 : 1764-9. 
147. Baumgard LH, Weber WJ, Kazmer GW, et al. (2002). Effects of selection for milk yield on growth hormone response to growth hormone releasing factor in growing Holstein calves. J Dairy Sci, 85 : 2529-40.

148. Peterson DG, Baumgard LH, Bauman DE (2002b). Short communication : milk fat response to low doses of tran-10, cis-12 conjugated linoleic acid (CLA). J Dairy Sci, 85 : 1764-6.

149. Kim YJ, Liu RH, Rychlik JL, Russell JB (2002). The enrichment of a ruminal bacterium (Megasphaera elsdenii YJ-4) that produces the trans-10, cis-12 isomer of conjugated linoleic acid. J Appl Microbiol, 92 : 976-82.

150. Giesy JG, McGuire MA, Shafii B, Hanson TW (2002). Effect of dose of calcium salts of conjugated linoleic acid (CLA) on percentage and fatty acid content of milk fat in midlactation holstein cows. $J$ Dairy Sci, 85 : 2023-9.

151. Corino C, Mourot J, Magni S, Pastorelli G, Rosi F (2002). Influence of dietary conjugated linoleic acid on growth, meat quality, lipogenesis, plasma leptin and physiological variables of lipid metabolism in rabbits. J Anim Sci, $80: 1020-8$.

152. Ramsay TG, Evock-Clover CM, Steele NC, Azain MJ (2001). Dietary conjugated linoleic acid alters fatty acid composition of pig skeletal muscle and fat. J Anim Sci, 79 : 2152-61.

153. Gatlin LA, See MT, Larick DK, Lin X, Odle J (2002). Conjugated linoleic acid in combination with supplemental dietary fat alters pork fat quality. J Nutr, 132 : 3105-12.

154. Joo ST, Lee JI, Ha YL, Park GB (2002). Effects of dietary conjugated linoleic acid on fatty acid composition, lipid oxidation, color, and water-holding capacity of pork loin. J Anim Sci, 80 : 108-12.

155. Tischendorf F, Schone F, Kirchheim U, Jahreis G (2002). Influence of a conjugated linoleic acid mixture on growth, organ weights, carcass traits and meat quality in growing pigs. J Anim Physiol Anim Nutr, (Berl) $86: 117-28$.

156. Glaser KR, Wenk C, Scheeder MR (2002). Effects of feeding pigs increasing levels of C 18:1 trans fatty acids on fatty acid composition of backfat and intramuscular fat as well as backfat firmness. ArchTierernahr, 56 : 117-30.

157. Kramer JK, Sehat N, Dugan ME, et al. (1998). Distributions of conjugated linoleic acid (CLA) isomers in tissue lipid classes of pigs fed a commercial CLA mixture determined by gas chromatography and silver ion-high-performance liquid chromatography. Lipids, 33 : 549-58.

158. Wiegand BR, Sparks JC, Parrish FC, Zimmerman DR (2002). Duration of feeding conjugated linoleic acid influences growth performance, carcass traits, and meat quality of finishing barrows. $J$ Anim Sci, 80 : 637-43.

159. Wiegand BR, Parrish FC, Swan JE, Larsen ST, Baas TJ (2001). Conjugated linoleic acid improves feed efficiency, decreases subcutaneous fat, and improves certain aspects of meat quality in stressgenotype pigs. J Anim Sci, 79 : 2187-95.

160. Médale F, Lefèvre F, Corraze G (2003). Qualité nutritionnelle et diététique des poissons : constituants de la chair et facteurs de variation. Cah Nutr Diet, $1: 37-44$. 
161. Girard S, Paquotte $P$ (2003). La consommation de produits de la pêche et de l'aquaculture en France. Cah Nutr Diet, $1: 17-28$.

162. Mariojouls C (2003). Perception de la qualité du poisson par le consommateur : composante et évolutions. Cah Nutr Diet, $1: 29-36$.

163. Fauconneau B (2003). La qualité des poissons d'élevage, un concept multifactioriel polymorphe. Cah Nutr Diet, 1 : 53-8.

164. Legrand P, Bourre JM, Descomps B, Durand G, Renaud S (2000). Lipides : apports nutritionnels conseillés pour la population française. Martin A éditeur. Tec et doc Lavoisier, 63-82.

165. FSSA (2003). Acides gras de la famille oméga 3 et système cardiovasculaire : intérêt nutritionnel et allégations. AFSSA, 10 juillet 2003.

Illustrations

\begin{tabular}{|c|c|c|c|}
\hline mm & $\mathrm{COOH}$ & Acide laurique & $12: 0$ \\
\hline MMn & $\mathrm{COOH}$ & Acide myristique & $14: 0$ \\
\hline MMM & $\mathrm{COOH}$ & Acide palmitique & $16: 0$ \\
\hline MMnm & $\mathrm{COOH}$ & Acide stéarique & $18: 0$ \\
\hline Mñm & $\mathrm{COOH}$ & Acide oléique & $18: 1(n-9)$ \\
\hline MصコM & $\mathrm{COOH}$ & Acide linoléique & $18: 2(n-6)$ \\
\hline MصصسM & $\mathrm{COOH}$ & Acide alpha-linolénique & $18: 3(n-3)$ \\
\hline Mصصص & $\mathrm{COOH}$ & Acide arachidonique & $20: 4(n-6)$ \\
\hline & $\mathrm{COOH}$ & EPA & $20: 5(n-3)$ \\
\hline مص & $\mathrm{COOH}$ & DHA, cervonique & $22: 6(n-3)$ \\
\hline Mmmm & $\mathrm{COOH}$ & Acide lignocérique & $24: 0$ \\
\hline momm & $\mathrm{COOH}$ & Acide nervonique & $24: 1(n-9)$ \\
\hline mmmm & $\mathrm{COOH}$ & Acide cérébronique & $24 h: 0$ \\
\hline MYMr & $\mathrm{COOH}$ & Acide phytanique & \\
\hline
\end{tabular}

Figure 1. Nomenclature des principaux acides gras. 


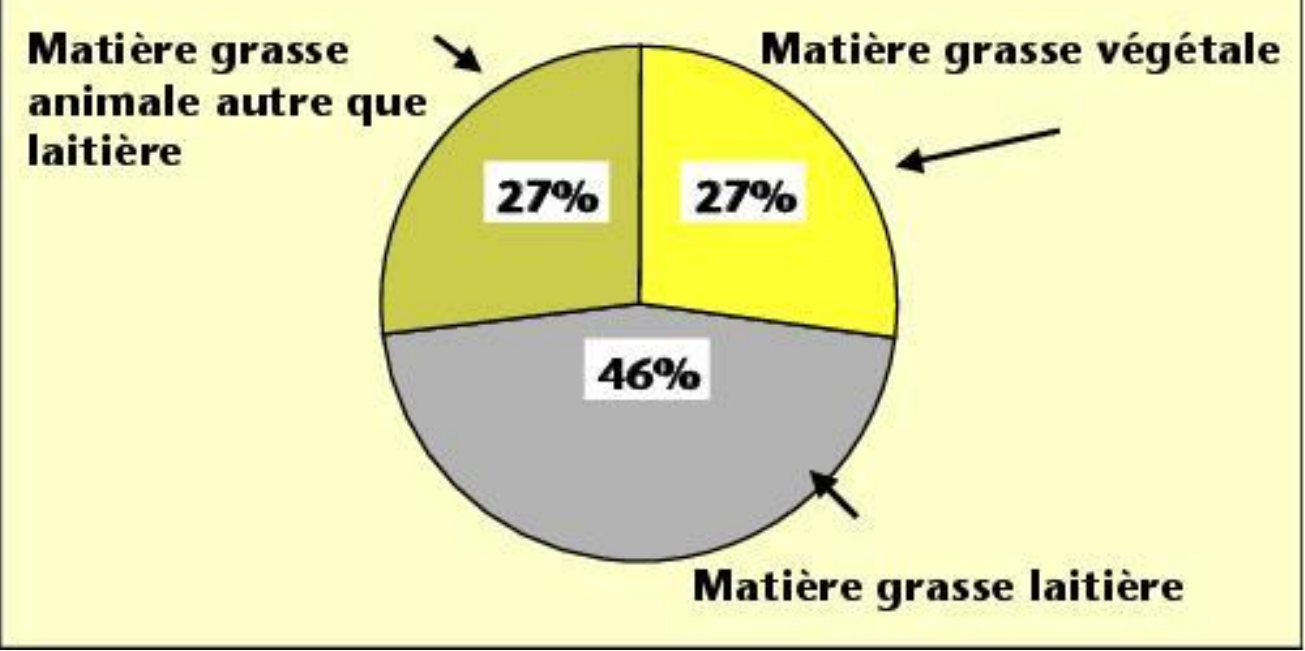

Figure 2. Contributions (\%) des matières grasses à l'apport quotidien en acide alpha-linolénique. D’après Combe, 2001 (Région Aquitaine).

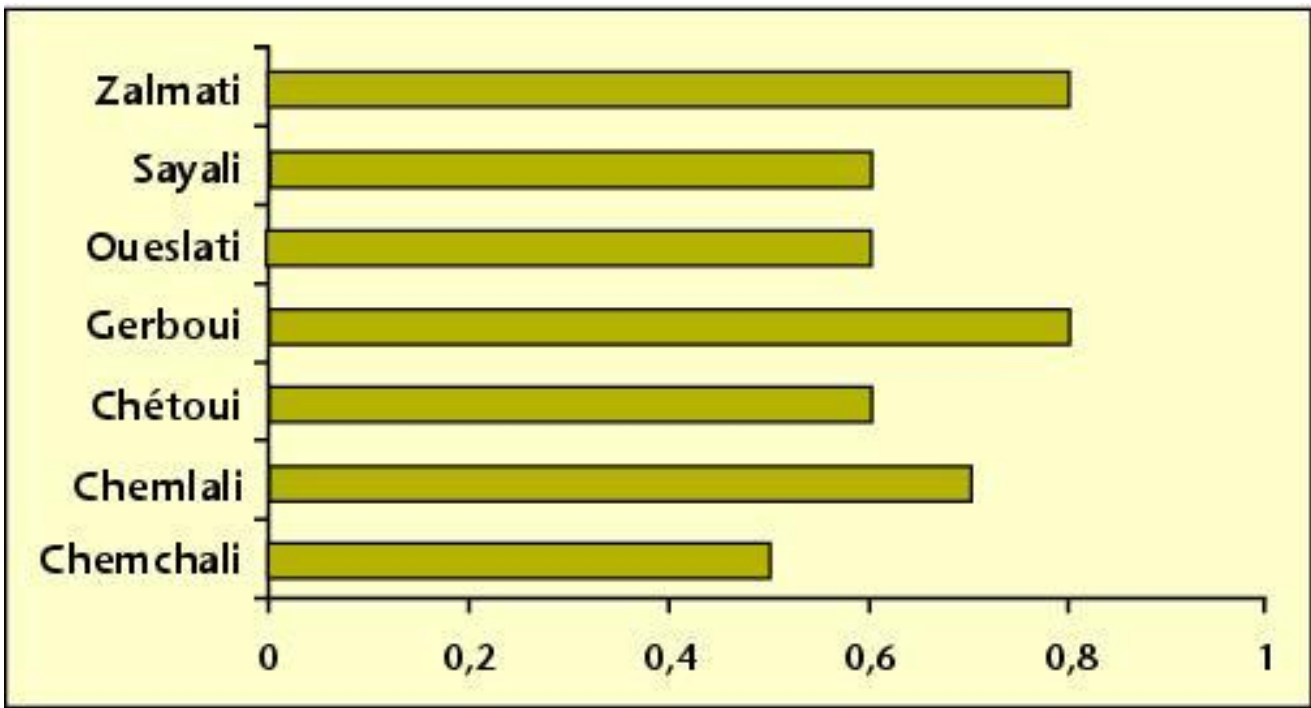

Figure 3. Acide 18:3 dans les sept variétés d'huile d'olive en pourcentage des acides gras totaux. D’après Abaza et al. [16]. 


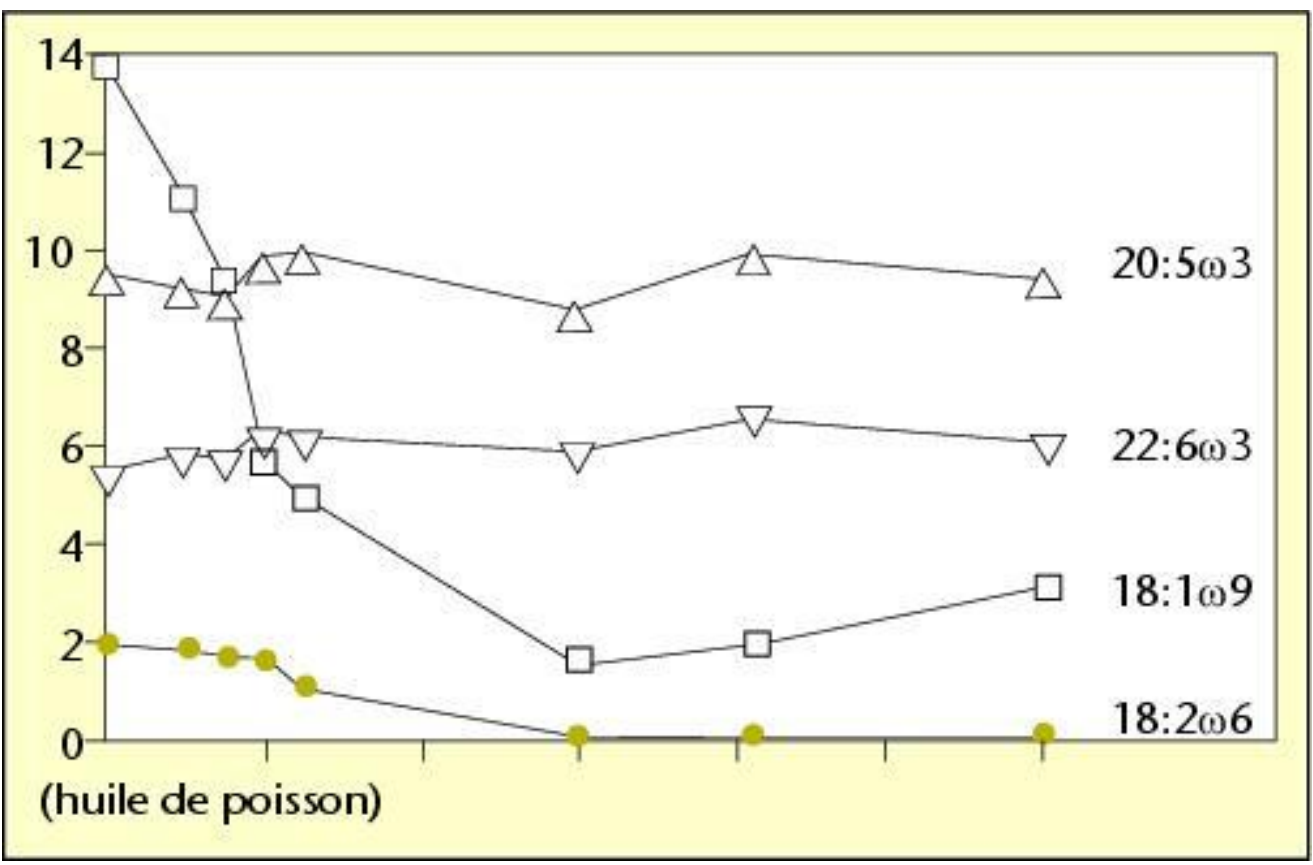

Figure 4. Hydrogénation par les micro-organismes du rumen (mouton) en pourcentage des acides gras. D'après Ashes et al. [17].

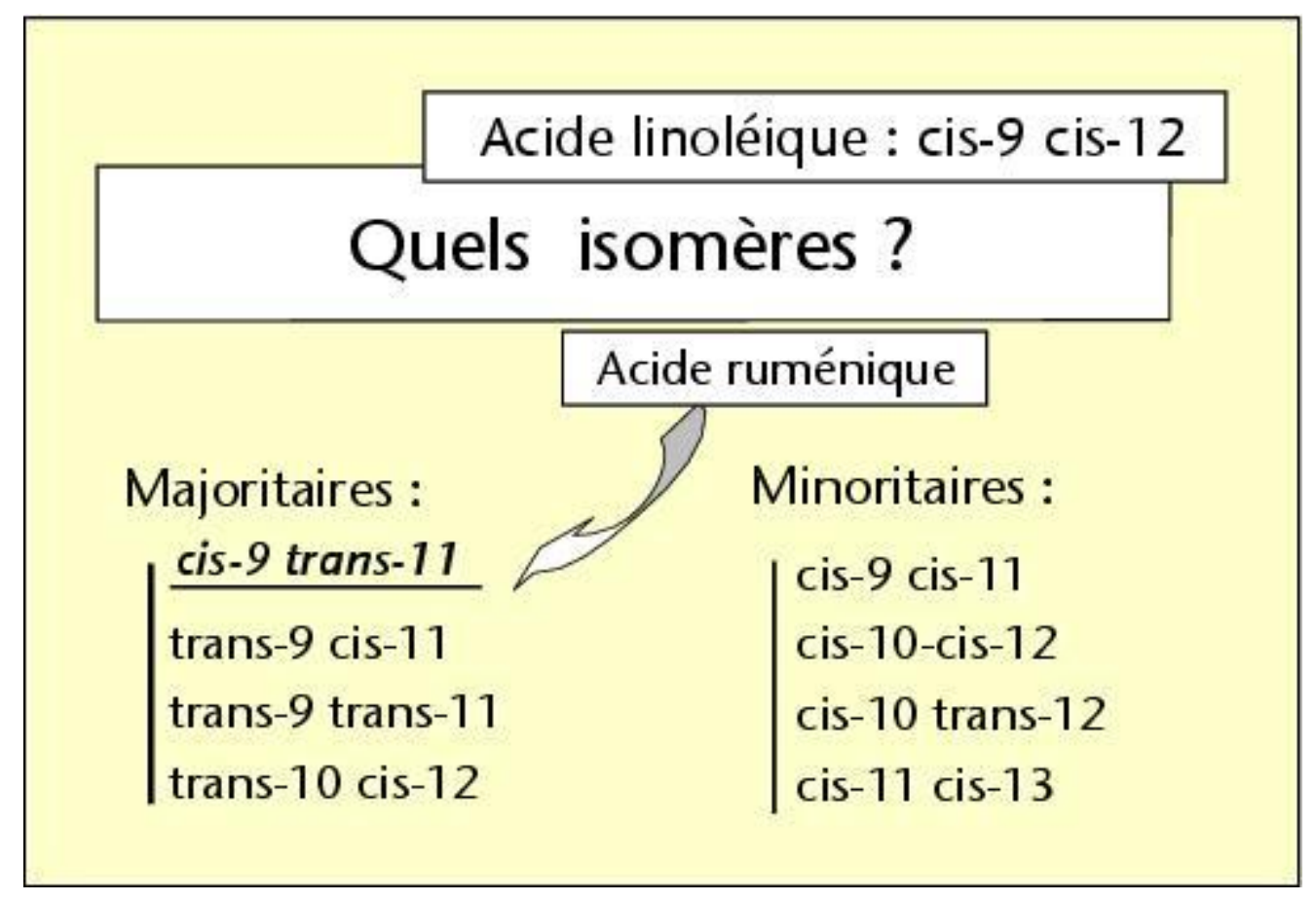

Figure 5. Formules chimiques des principaux acides linoléiques conjugués. 
- Attaque par les radicaux libres du 18:2w6

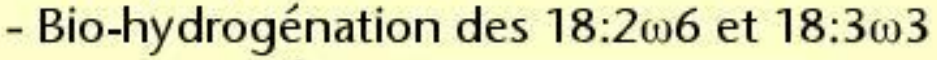

$\Longrightarrow 18: 0$ (acide stéarique)

- Delta-9-désaturase sur acide vaccénique

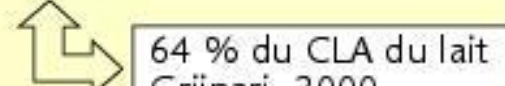

Oléique : $18: 1$ cis-9

Elaidique : $18: 1$ trans- 9

Vaccénique : 18:1 trans-11

Figure 6. Mécanismes de synthèse des acides linoléiques conjugués. 